\title{
Development of an N-Terminal BRD4 Bromodomain-Targeted Degrader
}

\author{
Anand Divakaran, ${ }^{\S}$ Huda Zahid, ${ }^{\dagger}$ Wenwei Lin, ${ }^{\ddagger}$ Taosheng Chen, ${ }^{\star}$ Daniel A. Harki, ${ }^{\S}{ }^{\dagger}$ and William C.K. \\ Pomerantz ${ }^{\dagger \& *}$
}

\author{
$\S$ Department of Medicinal Chemistry, University of Minnesota, 2231 6th St SE, Minneapolis, MN 55455, United States \\ † Department of Chemistry, University of Minnesota, 207 Pleasant St. SE, Minneapolis, MN55455, United States \\ $\$$ Department of Chemical Biology and Therapeutics, St. Jude Children's Research Hospital, Memphis, Tennessee 38105, \\ United States
}

\section{KEYWORDS}

BRD4-BD1 Inhibitor, BRD4 Degrader, BET Domain Selectivity, Epigenetic Reader Domain

ABSTRACT: Targeted protein degradation is a powerful induced-proximity tool to control cellular concentrations of native proteins
using small molecules. However, the design of selectivity in protein degradation remains challenging. In the case of Bromodomain
and Extra-Terminal (BET) family proteins, BRD4 has emerged as the primary therapeutic target over other family members BRD2, 3
and T, but strategies to selectively degrade BRD4 rely on the use of pan-BET inhibitors optimized for BRD4:E3 protein-ubiquitin
ligase (E3) ternary complex formation. Here, we report a potent and selective inhibitor for the first bromodomain of BRD4, iBRD4-
BD1 (IC 5 50 $12 \mathrm{nM}, 23-6200$-fold intra-BET selectivity). We further use this novel inhibitor to develop dBRD4-BD1 that induces
selective degradation of BRD4 at a DC $\mathrm{C}_{50}$ of $280 \mathrm{nM}$. The design of BRD4 selectivity up-front enables the study of BRD4 biology in the
absence of wider BET-inhibition, simplifies design of future BRD4-selective degraders as new E3 recruiting ligands are discovered,
and provides a tool to design additional heterobifunctional BRD4-selective probes.

Bromodomain and Extra-Terminal (BET) family proteins, BRD2, 3, 4 and testis-specific protein, BRDT, are essential epigenetic regulators of gene expression through molecular recognition of acetylated proteins. ${ }^{1}$ Of the three ubiquitously expressed BET proteins, BRD4 is accepted as the most disease-relevant target for inflammation and oncology; ${ }^{2-5}$ but few strategies exist to selectively target native BRD4 function. The tandem bromodomains (BD1 and BD2) are the most ligandable domains of BET proteins, but their selective targeting remains challenging due to a high degree of homology among the eight BET bromodomains., ${ }^{6,7}$ Although advances have been made from pan-BET inhibition to either pan-BD1 or -BD2 inhibition of BET proteins, ${ }^{8,9}$ potent inhibitors with high selectivity for individual BET bromodomains are yet to be reported.

As an alternative to inhibition, targeted protein degradation has emerged as a therapeutic modality leveraging event-driven pharmacology over traditional target occupancy models. ${ }^{10}$ Targeted degraders co-opt cellular proteostasis machinery, inducing proximity between cellular E3 protein-ubiquitin ligases (E3) and proteins of interest, resulting in proteasomal degradation of target proteins. Given their sub-stoichiometric mode of action, modularity in design and promise of targeting traditionally 'undruggable' targets, degraders have been reported for a wide variety of protein classes including BET proteins. ${ }^{11-13}$ BET-degraders have improved therapeutic efficacy compared to BET-inhibition alone, ${ }^{14}$ but both face challenges with dose-limiting toxicities including thrombocytopenia attributed to targeting BRD2 and BRD3. ${ }^{15}$ While selective degraders have been developed from promiscuous ligands, ${ }^{16}$ including selective BRD4-degraders from pan-BET inhibitors (Figure 1), ${ }^{17-19}$ the design of selectivity remains a non-trivial endeavor.

Here we report the design, synthesis, and characterization of a first-in-class BRD4-BD1 selective inhibitor, iBRD4-BD1 (Figure 1), with 23-6200-fold selectivity over ubiquitously expressed BET bromodomains. We use this inhibitor to test the efficacy of selective BRD4 degradation through BRD4-BD1 engagement. Design of our first-generation degrader, dBRD4-BD1, demonstrated sustained BRD4 degradation and unexpectedly increased BRD2 and BRD3 protein levels. This approach is distinct from previous BRD4-selective degraders as the use of a BRD4-BD1 inhibitor avoids reversible bromodomain inhibition of undegraded BET-proteins by a pan-BET ligand (Figure 1). 


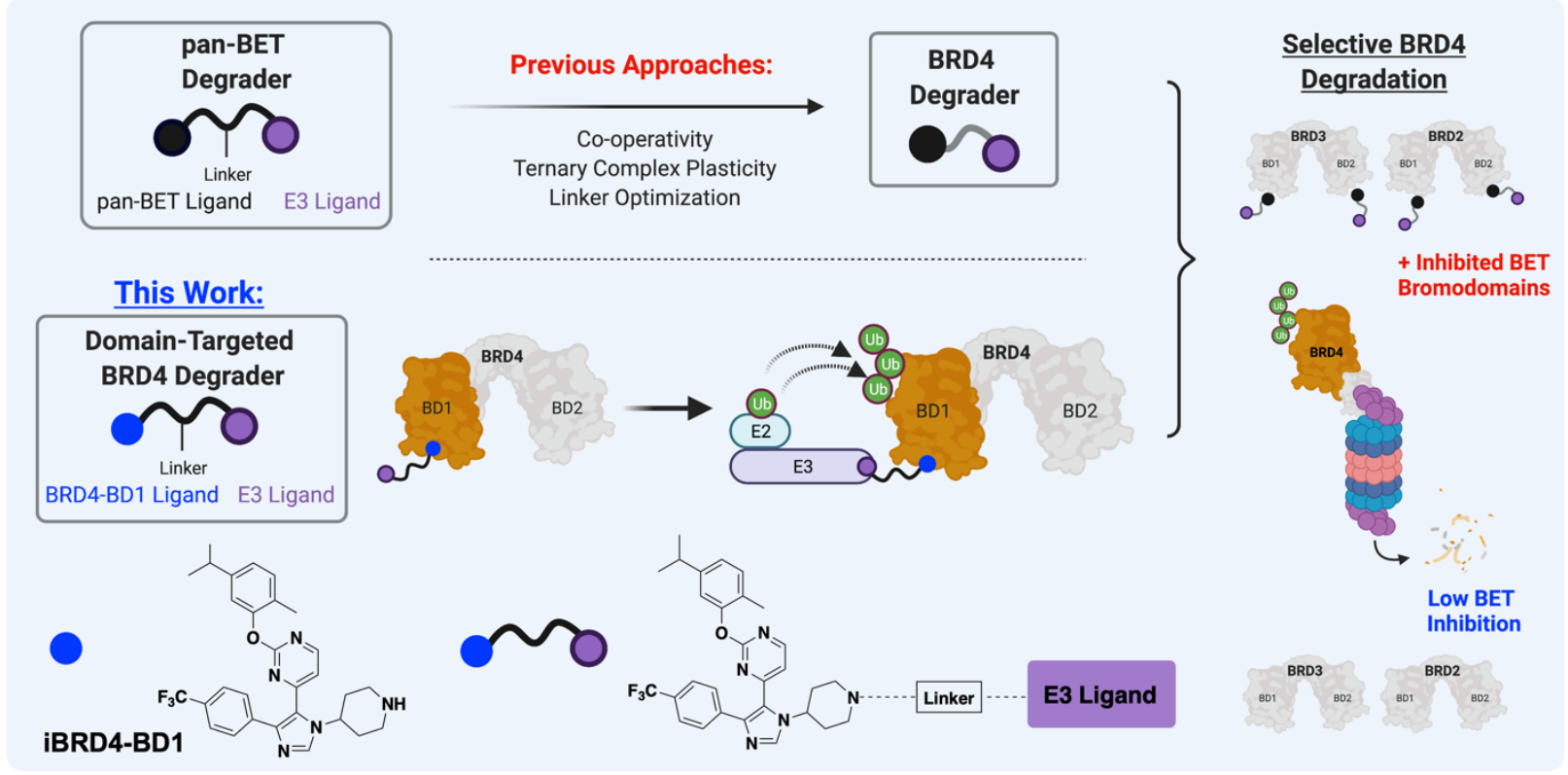

Figure 1: Strategies for selective BRD4 degradation. Previous approaches based on pan-BET ligands optimize linkers for BRD4-E3 ligase binding kinetics and ternary complex formation, whereas this work focuses on BRD4 degradation through selective engagement of its $\mathrm{N}$-terminal bromodomain.

Wang and coworkers have shown the expression of BRD4, not BRD2/3, correlate most strongly to sensitivity of BET degraders in lung cancer cells. ${ }^{20}$ Similar results have been observed in other cancers ${ }^{21-23}$ supporting BRD4 as the most relevant BET protein to target for degradation. ${ }^{24}$ We envisioned an approach using a ligand with high BRD4 specificity and affinity to degrade BRD4 in a cell line with high BRD4 sensitivity (e.g., multiple myeloma, MM.1S), but only a few molecules with high selectivity for inhibiting BRD4 exist. ${ }^{25,26}$ By leveraging selectivity properties and structural information of our BD1-selective inhibitors, ${ }^{27,28}$ we hypothesized we could degrade BRD4 through an individual bromodomain. ${ }^{29,30}$

Initially, it remained unclear whether BRD4 was amenable to degradation through BD1. Preferential BD2 engagement of previous degraders, ${ }^{31}$ coupled with higher chromatin occupancy of BD1 that leaves BD2 unliganded, ${ }^{32}$ suggested BRD4 degradation likely proceeds through BD2. To test these effects, we performed competition experiments on pan-BET-degrader, MZ1, using pan-BD1 and pan-BD2 selective inhibitors, iBET-BD1 and $\mathrm{BBET}-\mathrm{BD} 2 .^{9}$ In this case, neither BD1 nor BD2 inhibition prevented BRD4 degradation (Figure $2 \mathrm{~A}$ ), demonstrating either bromodomain can provide a suitable handle for degradation despite the preference of MZ1 to bind BRD4BD2 while forming a ternary complex with VHL. ${ }^{31}$ These experiments validated our strategy for domain-targeted BRD4 degradation.

In contrast to pan-BET bromodomain inhibitors, 1,4,5trisubstituted imidazoles such as V and UMN627 from our lab preferentially bind to BD1 of BRD4. These inhibitors achieve moderate selectivity in part by displacing a network of conserved waters from the BD1 acetyl-lysine binding site (Figure 2B). ${ }^{28,33}$ We hypothesized a vacant hydrophobic area surrounding a dimethyl-aryl ring could be better occupied by bulky aliphatic groups. From these studies, we found replacement of the 3,5-dimethyl substituents with a 2-methyl-5-isopropyl in iBRD4-BD1 (Figure 1) resulted in an increase in affinity and selectivity within the BET-family (BRD4-BD1 IC $\mathrm{I}_{50}=12 \mathrm{nM}$, 23-6200fold BET selectivity; Figure $2 \mathrm{C}$ ). A detailed discussion of the structure-activity-data will be reported elsewhere. Next, we evaluated the cellular engagement of BRD4 in a cellular thermal shift assay (CETSA) with previously established denaturation conditions. ${ }^{33,34}$ iBRD4-BD1 prevented the denaturation of BRD4 in a dose-dependent manner and showed stabilization of BRD4 at concentrations above $3 \mathrm{nM}$ (Figure 2D).

In cocrystal structures of $\mathbf{V}$ and UMN627 analogues, the piperidyl amine was oriented towards solvent (PDB ID: $6 \mathrm{MH1}$, 6WGX). As such, degrader dBRD4-BD1 (Figure 3A) was synthesized via conjugation of iBRD4-BD1 through a PEG linker attached to a 4-hydroxythalidomide analogue. This conjugate resulted in a modest loss of apparent binding to BRD4-BD1 ( $\mathrm{IC}_{50}=1.36 \mu \mathrm{M}$, Figure $\left.3 \mathrm{~B}\right)$. Due to poor solubility, increased DMSO was used in the assay ( $1 \%$, vs. $0.1 \% \mathrm{v} / \mathrm{v}$ used previously), also resulting in weaker binding of iBRD4-BD1 $\left(\mathrm{IC}_{50}=0.47 \mu \mathrm{M}\right.$ vs. $0.012 \mu \mathrm{M}$ in Figure 2D). 
To ensure dBRD4-BD1 forms a ternary complex of BRD4 with CRBN necessary for productive degradation, we used

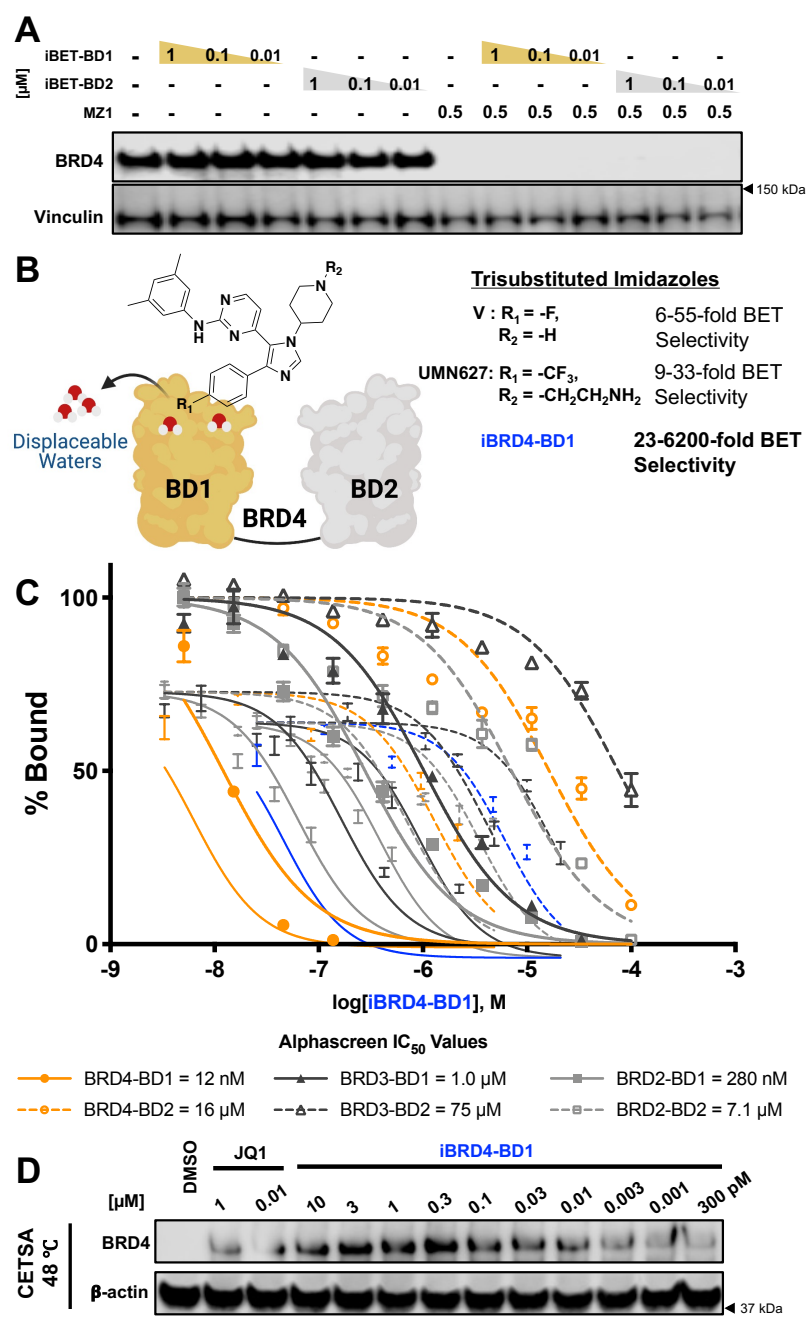

Figure 2: Role of BD1 in BRD4 degradation and biophysical characterization of iBRD4-BD1. (A) Competition of pan-BET degrader, $\mathrm{MZ1}$, with pan-BD1 or pan-BD2 inhibitors, iBETBD1/BD2. (B) Trisubstituted imidazoles with BETbromodomain selectivity for BRD4-BD1. (C) Commercial Alphascreen assay with BET-bromodomains from Reaction Biology. Data reported as mean of duplicate experiments. (D) Isothermal dose-response CETSA demonstrating target engagement of BRD4 in MM.1S cells after $1 \mathrm{~h}$ treatment.

a TR-FRET assay with GST-tagged BRD4 bromodomains and His-tagged CRBN (Figure $3 \mathrm{C}$ ). ${ }^{35}$ dBET1 demonstrates no selectivity between $\mathrm{BD} 1$ and $\mathrm{BD} 2$ to produce a high TRFRET signal with both bromodomains. However, dBRD4BD1 selectively produced a TR-FRET signal with BRD4-BD1 and not BD2, albeit to a lower amplitude than dBET1 (Figure 3D). Both dBRD4-BD1 and dBET1 also show a hook-effect at high concentrations, supporting ternary complex formation. Due to the directionality and distance dependence for effective FRET, the low amplitude is likely related to FRET-pair orientation. Compound concentrations required to produce maximal FRET signals and the corresponding hook-effect may be more indicative of ternary complex formation. Maximal FRET signals (denoted by ${ }^{*}$ ) were observed at low nanomolar concentrations for both dBET1 and dBRD4-BD1, suggesting selective and effective chemically induceddimerization of BRD4-BD1 and CRBN. Aggregation of dBRD4-BD1 and 4-hydroxythalidomide at concentrations above $10 \mu \mathrm{M}$ likely resulted in the increasing TR-FRET signal at these concentrations. Importantly, neither monovalent ligand iBRD4-BD1 nor 4-hydroxythalidomide could assemble ternary complexes in both bromodomains.

Encouraged by the positive biophysical results and insight into domain-selectivity, we assessed the ability to degrade BRD4 through BD1 alone. Despite the low TRFRET assay amplitude, dBRD4-BD1 demonstrated selective and durable BRD4 degradation $\left(D_{\max }=77 \%, D_{50}\right.$ $280 \mathrm{nM}$, Figure 4A and B), which diminished above concentrations of $5 \mu \mathrm{M}$ where formation of the productive ternary complex was disfavored due to the hook-effect. Degradation of BRD2 and 3 were not observed; conversely both were upregulated at concentrations where BRD4 was degraded. Overall, BRD4 was selectively degraded by dBRD4-BD1 and levels of BRD2 and 3 inversely correlated to BRD4, including at concentrations where the hook-effect was observed. This surprising effect on BRD2 and 3 was not observed with previous BRD4-selective degraders AT1, ZXH-3-26 and KB02-JQ1. ${ }^{17-19}$ Distinctively, all three use pan-BET ligands that likely occupy bromodomains of BRD2/3 and dampen a cellular feedback response to BRD4 degradation that is unaffected by iBRD4-BD1.

BET inhibition can have a stronger effect on cMyc concentrations relative to BET-degradation. ${ }^{36}$ Since proliferation of the MM.1S cell-line is heavily cMyc driven $^{37}$ and BD1 inhibition increases levels of cMyc in some cases, $^{28,38}$ we compared the anti-proliferative effects of our compounds with cMyc expression. dBRD4BD1 does not downregulate cMyc until near maximal BRD4 degradation is achieved, likely leading to the lower observed cytotoxicity with dBRD4-BD1 relative to iBRD4BD1 (Figure S1). Although cMyc is absent at higher dBRD4BD1 concentrations where the hook-effect is observed, inhibition of BET bromodomains alone at these concentrations, rather than BRD4 degradation, may be sufficient to affect cMyc expression.

Next, we evaluated the effects of dBRD4-BD1 over an extended incubation period to assess weaker degradation targets. A potential benefit of the linker attachment point to iBRD4-BD1 is the effect on kinase binding. Trisubstituted imidazoles are known inhibitors of the p38 $\alpha$ kinase and the piperidine of iBRD4-BD1 analogues 
(e.g., PDB ID: 1OUK) occupies a region oriented towards the kinase activation loop. Gratifyingly, p38 $\alpha$ levels
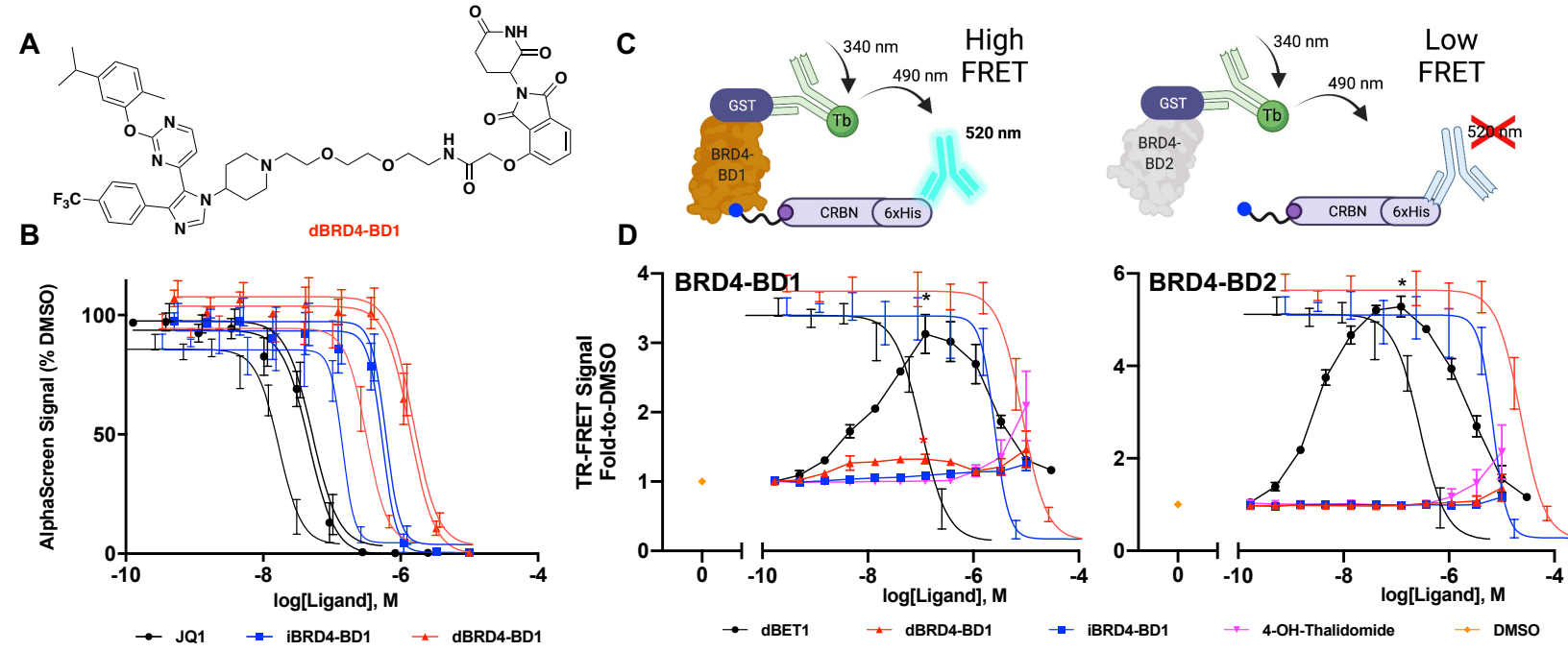

Figure 3: Biophysical characterization of dBRD4-BD1. (A) Structure of dBRD4-BD1. (B) Alphascreen binding assay with 9xHis-BRD4$B D 1$, reported as mean \pm SD of three independent trials performed in duplicate. (C) Schematic of TR-FRET assay to determine complex formation of BRD4 bromodomains with CRBN via bivalent molecules. (D) TR-FRET ternary complexation assay between His-CRBN and GST-BRD4-BD1 (left), or GST-BRD4-BD2 (right); reported as mean \pm SD of three independent trials performed in quadruplicate. FRET-maxima below $1 \mu \mathrm{M}$ denoted by *

remain unchanged even after extended treatment periods to suggest $\mathrm{p} 38 \alpha$ is not engaged by dBRD4-BD1 (Figure 4C).

In contrast to $\mathrm{p} 38 \alpha$ levels in the time-course study, the degradation half-life of BRD4 was $3.3 \mathrm{~h}$ with maximal degradation achieved after $8 \mathrm{~h}$ (Figure 4C). Similar to our earlier observation, concentrations of BRD2 and BRD3 increased after the 8 and $12 \mathrm{~h}$ timepoints respectively. Modest recovery in cMyc expression was observed at later timepoints. Widespread effects have been reported in response to BET-inhibition and degradation. ${ }^{39,40}$ Upregulation of proteins in response to BRD4 degradation may be broader than our set of evaluated proteins, and cellular toxicity at these later time points may have additional effects.

To verify the mechanism of degradation, we performed competition experiments with domain-selective BET and proteasome inhibitors. iBET-BD1 competitively rescued BRD4 degradation whereas iBET-BD2 was ineffective (Figure 4D). Additionally, BRD4 degradation was rescued with proteasome and neddylation inhibitors, MG-132 and MLN4924. These results together indicate degradation by dBRD4-BD1 was dependent on BD1 and proceeded via ubiquitination and proteasome- dependent pathways.

In summary, given the disease relevance of BRD4specific function and to address the lack of tools to selectively target BRD4, we leveraged the unique properties of BRD4- and domain-selective BET inhibitors. iBRD4-BD1 notably has >23-fold selectivity for BRD4-BD1 over other BET bromodomains, the highest reported to date. Moreover, this is the first instance of selective endogenous BRD4 degradation through an individual bromodomain, which produces divergent effects on $\mathrm{BRD} 2 / 3$ relative to previous BRD4 degraders.

Prior to this study, the design of BRD4-selective heterobifunctional ligands relied on optimizing pan-BET ligands for interaction kinetics (e.g., BRD4-BD2 with AT1) ${ }^{17}$ or optimizing linker geometries for ternary complex formation (e.g., BRD4-BD1 with ZXH-3-26). ${ }^{18}$ This process is cumbersome and a major limitation remains in availability of the BET-ligand to bind other BET bromodomains aside from the BRD4-ternary complex, which obscures biological effects and may result in toxicity related to targeting BRD2/3.15 The approach presented here highlights the utility of a BRD4-selective inhibitor in circumventing the need for iterative optimization of linker/complex interactions. We envision our new BRD4 ligand, and this strategy, will simplify future BRD4selective degrader development using new E3-ligase ligands that engender further selectivity and efficacy, and more broadly facilitate the design of additional selective BRD4-targeting heterobifunctional modalities beyond degraders. These new tools will be especially beneficial in the study of domain-specific BRD4 biology, which will be the focus of our future work. 

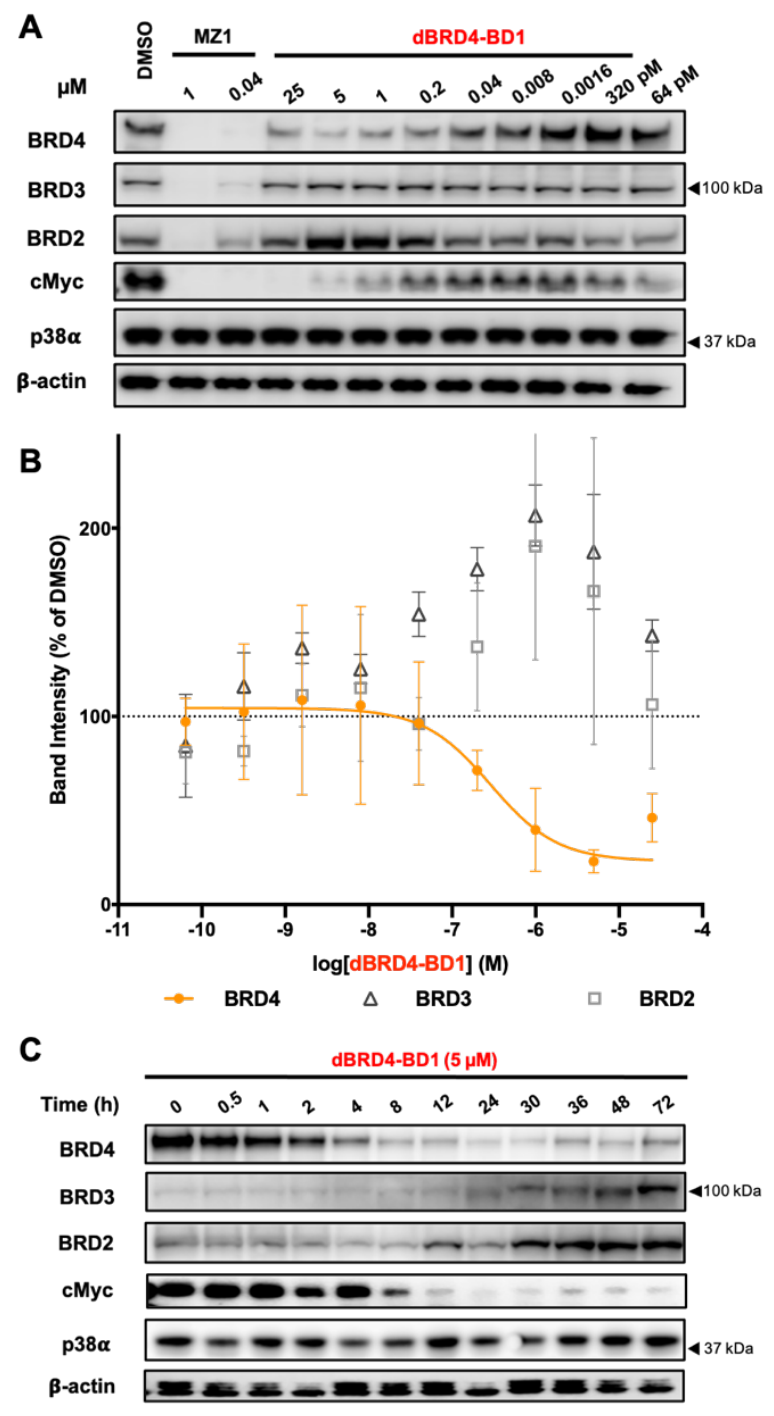

D

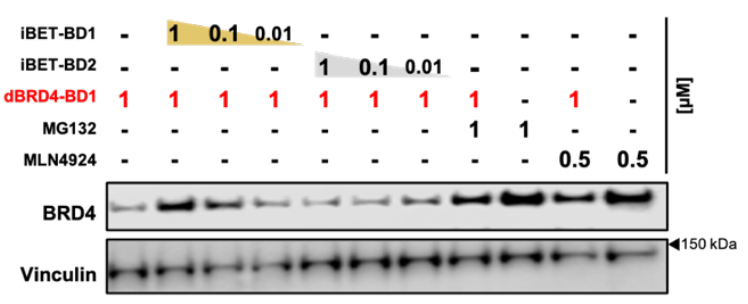

Figure 4: BRD4 degradation in MM.1S cells. (A) Representative blots for BRD4 degradation after $24 \mathrm{~h}$ treatment. (B) Quantified densitometry for three biological replicates of blots from (A). (C) Time-course study of BRD4 degradation by dBRD4-BD1. (D) Rescue of BRD4 degradation using pan-BD1, proteasome and neddylation inhibitors, but not pan-BD2 inhibitor, iBET-BD2. Refer to Figure $2 \mathrm{~A}$ for untreated control from the same gel. 


\section{ASSOCIATED CONTENT}

\section{Supporting Information}

The Supporting Information is available free of charge on the ACS Publications website.

Experimental methods, characterization, and supplementary data (PDF)

\section{AUTHOR INFORMATION}

\section{Corresponding Author}

*E-mail: daharki@umn.edu and wcp@umn.edu

\section{Author Contributions}

A.D., D.A.H. and W.C.K.P. conceived project; A.D. designed and synthesized molecules, performed cellular experiments and wrote manuscript. H.Z. and W.L. designed and performed biophysical experiments. T.C., D.A.H and W.C.K.P. supervised study. All authors contributed to writing and review of the manuscript and have given approval to this final version.

\section{Funding Sources}

This research was supported by the National Institutes of Health's National Center for Advancing Translational Sciences, grant UL1TR002494. A.D. was supported by the UMN Doctoral Dissertation Fellowship and NIH chemistry-biology interface training grant (T32-GM008700/ T32-GM132029-01). H.Z. was supported by UMN IEM Engineering in Medicine Doctoral Fellowship 2020. D.H. acknowledges funding from the Masonic Cancer Center at the University of Minnesota with resources from Minnesota Masonic Charities. T.C. is supported by National Institute of General Medical Sciences of the National Institutes of Health under award number R35GM118041. The content is solely the responsibility of the authors and does not necessarily represent the official views of the supporting organizations.

\section{Notes}

The authors declare no competing financial interests.

\section{Acknowledgments}

The authors would like to thank Dr. Siva Talluri and Dr. Peter Ycas for their intellectual contributions to this project. Figures were created using GraphPad Prism and BioRender. iBET-BD1 and iBET-BD2 were supplied by the Structural Genomics Consortium under an Open Science Trust Agreement: http://www.thesgc.org/click-trust. The His-CRBN protein was prepared by the Protein Production Facility at St. Jude Children's Research Hospital.

\section{ABBREVIATIONS}

$\mathrm{BET}$, Bromodomain and Extra-Terminal; BRD2/3/4/T, Bromodomain-containing protein 2/3/4/T; Myc, MYC proto-oncogene, bHLH transcription factor; BD1, N-terminal BET bromodomain; BD2, C-terminal BET bromodomain; E3, protein-ubiquitin ligase; CRBN, cereblon; CETSA, Cellular Thermal Shift Assay; SAR, Structure-Activity Relationship; PEG, poly-ethylene glycol; DMSO, dimethyl sulfoxide; TR-FRET, Time-Resolved-Förster Resonance Energy Transfer; GST, Glutathione S-Transferase; TFA, trifluoroacetic acid.

\section{REFERENCES}

(1) Muller, S.; Filippakopoulos, P.; Knapp, S. Bromodomains as Therapeutic Targets. Expert Rev. Mol. Med. 2011, 13 (September), e29.

(2) Nabet, B.; Roberts, J. M.; Buckley, D. L.; Paulk, J.; Dastjerdi, S.; Yang, A.; Leggett, A. L.; Erb, M. A.; Lawlor, M. A.; Souza, A.; Scott, T. G.; Vittori, S.; Perry, J. A.; Qi, J.; Winter, G. E.; Wong, K. K.; Gray, N. S.; Bradner, J. E. The DTAG System for Immediate and Target-Specific Protein Degradation. Nat. Chem. Biol. 2018, 14 (5), 431441.

(3) Runcie, A. C.; Zengerle, M.; Chan, K. H.; Testa, A.; Van Beurden, L.; Baud, M. G. J.; Epemolu, O.; Ellis, L. C. J.; Read, K. D.; Coulthard, V.; Brien, A.; Ciulli, A. Optimization of a "Bump-and-Hole" Approach to Allele-Selective BET Bromodomain Inhibition. Chem. Sci. 2018, 9 (9), 2452-2468. 
Delmore, J. E.; Issa, G. C.; Lemieux, M. E.; Rahl, P. B.; Shi, J.; Jacobs, H. M.; Kastritis, E.; Gilpatrick, T.; Paranal, R. M.; Qi, J.; Chesi, M.; Schinzel, A. C.; McKeown, M. R.; Heffernan, T. P.; Vakoc, C. R.; Bergsagel, P. L.; Ghobrial, I. M.; Richardson, P. G.; Young, R. A.; Hahn, W. C.; Anderson, K. C.; Kung, A. L.; Bradner, J. E.; Mitsiades, C. S. BET Bromodomain Inhibition as a Therapeutic Strategy to Target C-Myc. Cell 2011, 146 (6), 904-917.

(5) Mertz, J. A.; Conery, A. R.; Bryant, B. M.; Sandy, P.; Balasubramanian, S.; Mele, D. A.; Bergeron, L.; Sims, R. J. Targeting MYC Dependence in Cancer by Inhibiting BET Bromodomains. Proc. Natl. Acad. Sci. 2011, 108 (40), 16669-16674.

(6) Filippakopoulos, P.; Picaud, S.; Mangos, M.; Keates, T.; Lambert, J. P.; Barsyte-Lovejoy, D.; Felletar, I.; Volkmer, R.; Müller, S.; Pawson, T.; Gingras, A. C.; Arrowsmith, C. H.; Knapp, S. Histone Recognition and Large-Scale Structural Analysis of the Human Bromodomain Family. Cell 2012, 149 (1), 214-231.

Filippakopoulos, P.; Qi, J.; Picaud, S.; Shen, Y.; Smith, W. B.; Fedorov, O.; Morse, E. M.; Keates, T.; Hickman, T. T.; Felletar, I.; Philpott, M.; Munro, S.; McKeown, M. R.; Wang, Y.; Christie, A. L.; West, N.; Cameron, M. J.; Schwartz, B.; Heightman, T. D.; La Thangue, N.; French, C. A.; Wiest, O.; Kung, A. L.; Knapp, S.; Bradner, J. E. Selective Inhibition of BET Bromodomains. Nature 2010, 468 (7327), 1067-1073.

(8) Faivre, E. J.; McDaniel, K. F.; Albert, D. H.; Mantena, S. R.; Plotnik, J. P.; Wilcox, D.; Zhang, L.; Bui, M. H.; Sheppard, G. S.; Wang, L.; Sehgal, V.; Lin, X.; Huang, X.; Lu, X.; Uziel, T.; Hessler, P.; Lam, L. T.; Bellin, R. J.; Mehta, G.; Fidanze, S.; Pratt, J. K.; Liu, D.; Hasvold, L. A.; Sun, C.; Panchal, S. C.; Nicolette, J. J.; Fossey, S. L.; Park, C. H.; Longenecker, K.; Bigelow, L.; Torrent, M.; Rosenberg, S. H.; Kati, W. M.; Shen, Y. Selective Inhibition of the BD2 Bromodomain of BET Proteins in Prostate Cancer. Nature 2020, 578 (7794), 306-310.

(9) Gilan, O.; Rioja, I.; Knezevic, K.; Bell, M. J.; Yeung, M. M.; Harker, N. R.; Lam, E. Y. N.; Chung, C.; Bamborough, P.; Petretich, M.; Urh, M.; Atkinson, S. J.; Bassil, A. K.; Roberts, E. J.; Vassiliadis, D.; Burr, M. L.; Preston, A. G. S.; Wellaway, C.; Werner, T.; Gray, J. R.; Michon, A. M.; Gobbetti, T.; Kumar, V.; Soden, P. E.; Haynes, A.; Vappiani, J.; Tough, D. F.; Taylor, S.; Dawson, S. J.; Bantscheff, M.; Lindon, M.; Drewes, G.; Demont, E. H.; Daniels, D. L.; Grandi, P.; Prinjha, R. K.; Dawson, M. A. Selective Targeting of BD1 and BD2 of the BET Proteins in Cancer and Immunoinflammation. Science. 2020, 368 (6489), 387-394.

(10) Lai, A. C.; Crews, C. M. Induced Protein Degradation: An Emerging Drug Discovery Paradigm. Nature Reviews Drug Discovery. Nature Publishing Group February 2, 2017, pp 101-114.

(11) Feral, A.; Laconde, G.; Amblard, M.; Masurier, N. PROteolysis TArgetting Chimeras (PROTACs) Strategy Applied to Kinases: Recent Advances. Adv. Ther. 2020, 3 (11), 2000148.

(12) Vogelmann, A.; Robaa, D.; Sippl, W.; Jung, M. Proteolysis Targeting Chimeras (PROTACs) for Epigenetics Research. Current Opinion in Chemical Biology. Elsevier Ltd August 1, 2020, pp 8-16.

(13) Flanagan, J. J.; Neklesa, T. K. Targeting Nuclear Receptors with PROTAC Degraders. Molecular and Cellular Endocrinology. Elsevier Ireland Ltd August 1, 2019, p 110452.

(14) Yang, C. Y.; Qin, C.; Bai, L.; Wang, S. Small-Molecule PROTAC Degraders of the Bromodomain and Extra Terminal (BET) Proteins - A Review. Drug Discovery Today: Technologies. Elsevier Ltd April 1, 2019, pp 4351.

(15) Stonestrom, A. J.; Hsu, S. C.; Jahn, K. S.; Huang, P.; Keller, C. A.; Giardine, B. M.; Kadauke, S.; Campbell, A. E.; Evans, P.; Hardison, R. C.; Blobel, G. A. Functions of BET Proteins in Erythroid Gene Expression. Blood 2015, 125 (18), 2825-2834.

(16) Bondeson, D. P.; Smith, B. E.; Burslem, G. M.; Buhimschi, A. D.; Hines, J.; Jaime-Figueroa, S.; Wang, J.; Hamman, B. D.; Ishchenko, A.; Crews, C. M. Lessons in PROTAC Design from Selective Degradation with a Promiscuous Warhead. Cell Chem. Biol. 2018, 25 (1), 78-87.e5.

(17) Gadd, M. S.; Testa, A.; Lucas, X.; Chan, K. H.; Chen, W.; Lamont, D. J.; Zengerle, M.; Ciulli, A. Structural Basis of PROTAC Cooperative Recognition for Selective Protein Degradation. Nat. Chem. Biol. 2017, 13 (5), 514521.

(18) Nowak, R. P.; Deangelo, S. L.; Buckley, D.; He, Z.; Donovan, K. A.; An, J.; Safaee, N.; Jedrychowski, M. P.; Ponthier, C. M.; Ishoey, M.; Zhang, T.; Mancias, J. D.; Gray, N. S.; Bradner, J. E.; Fischer, E. S. Plasticity in Binding Confers Selectivity in Ligand-Induced Protein Degradation Article. Nat. Chem. Biol. 2018, 14 (7), 706- 
714.

(19) Zhang, X.; Crowley, V. M.; Wucherpfennig, T. G.; Dix, M. M.; Cravatt, B. F. Electrophilic PROTACs That Degrade Nuclear Proteins by Engaging DCAF16. Nat. Chem. Biol. 2019, 15 (7), 737-746.

(20) Zong, D.; Gu, J.; Cavalcante, G. C.; Yao, W.; Zhang, G.; Wang, S.; Owonikoko, T. K.; He, X.; Sun, S. Y. BRD4 Levels Determine the Response of Human Lung Cancer Cells to BET Degraders That Potently Induce Apoptosis through Suppression of Mcl-1. Cancer Res. 2020, 80 (11), 2380-2393.

(21) Wong, A. S. L.; Choi, G. C. G.; Cui, C. H.; Pregernig, G.; Milani, P.; Adam, M.; Perli, S. D.; Kazer, S. W.; Gaillard, A.; Hermann, M.; Shalek, A. K.; Fraenkel, E.; Lu, T. K. Multiplexed Barcoded CRISPR-Cas9 Screening Enabled by CombiGEM. Proc. Natl. Acad. Sci. U. S. A. 2016, 113 (9).

(22) Shi, J.; Wang, E.; Milazzo, J. P.; Wang, Z.; Kinney, J. B.; Vakoc, C. R. Discovery of Cancer Drug Targets by CRISPR-Cas9 Screening of Protein Domains. Nat. Biotechnol. 2015, 33 (6), 661-667.

(23) Xiang, T.; Bai, J. yu; She, C.; Yu, D. jiang; Zhou, X. zhong; Zhao, T. lan. Bromodomain Protein BRD4 Promotes Cell Proliferation in Skin Squamous Cell Carcinoma. Cell. Signal. 2018, 42, 106-113.

(24) Wu, S.; Jiang, Y.; Hong, Y.; Chu, X.; Zhang, Z.; Tao, Y.; Fan, Z.; Bai, Z.; Li, X.; Chen, Y.; Li, Z.; Ding, X.; Lv, H.; Du, X.; Lim, S. L.; Zhang, Y.; Huang, S.; Lu, J.; Pan, J.; Hu, S. BRD4 PROTAC Degrader ARV-825 Inhibits T-Cell Acute Lymphoblastic Leukemia by Targeting “Undruggable” Myc-Pathway Genes. Cancer Cell Int. 2021, 21 (1).

(25) Ouyang, L.; Zhang, L.; Liu, J.; Fu, L.; Yao, D.; Zhao, Y.; Zhang, S.; Wang, G.; He, G.; Liu, B. Discovery of a SmallMolecule Bromodomain-Containing Protein 4 (BRD4) Inhibitor That Induces AMP-Activated Protein KinaseModulated Autophagy-Associated Cell Death in Breast Cancer. J. Med. Chem. 2017, 60 (24), 9990-10012.

(26) Liu, Z.; Chen, H.; Wang, P.; Li, Y.; Wold, E. A.; Leonard, P. G.; Joseph, S.; Brasier, A. R.; Tian, B.; Tian, B.; Zhou, J.; Zhou, J.; Zhou, J. Discovery of Orally Bioavailable Chromone Derivatives as Potent and Selective BRD4 Inhibitors: Scaffold Hopping, Optimization, and Pharmacological Evaluation. J. Med. Chem. 2020, 63 (10), 5242-5256.

(27) Divakaran, A.; Talluri, S. K.; Ayoub, A. M.; Mishra, N.; Cui, H.; Widen, J. C.; Berndt, N.; Zhu, J.-Y.; Carlson, A. S.; Topczewski, J. J.; Schönbrunn, E.; Harki, D. A.; Pomerantz, W. C. K. Molecular Basis for the N-Terminal Bromodomain and Extra Terminal (BET) Family Selectivity of a Dual Kinase-Bromodomain Inhibitor. J. Med. Chem. 2018, 61, 9316-9334.

(28) Cui, H.; Divakaran, A.; Pandey, A. K.; Johnson, J. A.; Zahid, H.; Hoell, Z. J.; Ellingson, M. O.; Shi, K.; Aihara, H.; Harki, D. A.; Pomerantz, W. C. K. Selective N-Terminal BET Bromodomain Inhibitors by Targeting NonConserved Residues and Structured Water Displacement**. Angew. Chemie - Int. Ed. 2021, 60 (3), 12201226.

(29) Petretich, M.; Demont, E. H.; Grandi, P. Domain-Selective Targeting of BET Proteins in Cancer and Immunological Diseases. Current Opinion in Chemical Biology. Elsevier Ltd August 1, 2020, pp 184-193.

(30) Tang, P.; Zhang, J.; Liu, J.; Chiang, C. M.; Ouyang, L. Targeting Bromodomain and Extraterminal Proteins for Drug Discovery: From Current Progress to Technological Development. J. Med. Chem. 2021, 64 (5), 24192435.

(31) Zengerle, M.; Chan, K. H.; Ciulli, A. Selective Small Molecule Induced Degradation of the BET Bromodomain Protein BRD4. ACS Chem. Biol. 2015, 10 (8), 1770-1777.

(32) Tyler, D. S.; Vappiani, J.; Cañeque, T.; Lam, E. Y. N.; Ward, A.; Gilan, O.; Chan, Y. C.; Hienzsch, A.; Rutkowska, A.; Werner, T.; Wagner, A. J.; Lugo, D.; Gregory, R.; Molina, C. R.; Garton, N.; Wellaway, C. R.; Jackson, S.; Macpherson, L.; Figueiredo, M.; Stolzenburg, S.; Bell, C. C.; House, C.; Dawson, S. J.; Hawkins, E. D.; Drewes, G.; Prinjha, R. K.; Rodriguez, R.; Grandi, P.; Dawson, M. A. Click Chemistry Enables Preclinical Evaluation of Targeted Epigenetic Therapies. Science. 2017, 356 (6345), 1397-1401.

(33) Divakaran, A.; Talluri, S. K.; Ayoub, A. M.; Mishra, N. K.; Cui, H.; Widen, J. C.; Berndt, N.; Zhu, J. Y.; Carlson, A. S.; Topczewski, J. J.; Schonbrunn, E. K.; Harki, D. A.; Pomerantz, W. C. K. Molecular Basis for the N-Terminal Bromodomain-and-Extra-Terminal-Family Selectivity of a Dual Kinase-Bromodomain Inhibitor. J. Med. Chem. 2018, 61 (20), 9316-9334.

(34) Jafari, R.; Almqvist, H.; Axelsson, H.; Ignatushchenko, M.; Lundbäck, T.; Nordlund, P.; Molina, D. M. The Cellular Thermal Shift Assay for Evaluating Drug Target Interactions in Cells. Nat. Protoc. 2014, 9 (9), 2100- 
2122.

(35) Lin, W.; Chen, T. General Stepwise Approach to Optimize a TR-FRET Assay for Characterizing the BRD/PROTAC/CRBN Ternary Complex. ACS Pharmacol. Transl. Sci. 2021, 4 (2), 941-952.

Devaiah, B. N.; Mu, J.; Akman, B.; Uppal, S.; Weissman, J. D.; Cheng, D.; Baranello, L.; Nie, Z.; Levens, D.; Singer, D. S. MYC Protein Stability Is Negatively Regulated by BRD4. Proc. Natl. Acad. Sci. U. S. A. 2020, 117 (24), 13457-13467.

(37) Lovén, J.; Hoke, H. A.; Lin, C. Y.; Lau, A.; Orlando, D. A.; Vakoc, C. R.; Bradner, J. E.; Lee, T. I.; Young, R. A. Selective Inhibition of Tumor Oncogenes by Disruption of Super-Enhancers. Cell 2013, 153 (2), 320-334.

(38) Raux, B.; Voitovich, Y.; Derviaux, C.; Lugari, A.; Rebuffet, E.; Milhas, S.; Priet, S.; Roux, T.; Trinquet, E.; Guillemot, J. C.; Knapp, S.; Brunel, J. M.; Fedorov, A. Y.; Collette, Y.; Roche, P.; Betzi, S.; Combes, S.; Morelli, $X$. Exploring Selective Inhibition of the First Bromodomain of the Human Bromodomain and Extra-Terminal Domain (BET) Proteins. J. Med. Chem. 2016, 59 (4), 1634-1641.

(39) Bandopadhayay, P.; Piccioni, F.; O’Rourke, R.; Ho, P.; Gonzalez, E. M.; Buchan, G.; Qian, K.; Gionet, G.; Girard, E.; Coxon, M.; Rees, M. G.; Brenan, L.; Dubois, F.; Shapira, O.; Greenwald, N. F.; Pages, M.; Balboni Iniguez, A.; Paolella, B. R.; Meng, A.; Sinai, C.; Roti, G.; Dharia, N. V.; Creech, A.; Tanenbaum, B.; Khadka, P.; Tracy, A.; Tiv, H. L.; Hong, A. L.; Coy, S.; Rashid, R.; Lin, J. R.; Cowley, G. S.; Lam, F. C.; Goodale, A.; Lee, Y.; Schoolcraft, K.; Vazquez, F.; Hahn, W. C.; Tsherniak, A.; Bradner, J. E.; Yaffe, M. B.; Milde, T.; Pfister, S. M.; Qi, J.; Schenone, M.; Carr, S. A.; Ligon, K. L.; Kieran, M. W.; Santagata, S.; Olson, J. M.; Gokhale, P. C.; Jaffe, J. D.; Root, D. E.; Stegmaier, K.; Johannessen, C. M.; Beroukhim, R. Neuronal Differentiation and Cell-Cycle Programs Mediate Response to BET-Bromodomain Inhibition in MYC-Driven Medulloblastoma. Nat. Commun. 2019, 10 (1).

(40) Winter, G. E.; Mayer, A.; Buckley, D. L.; Erb, M. A.; Roderick, J. E.; Vittori, S.; Reyes, J. M.; di lulio, J.; Souza, A.; Ott, C. J.; Roberts, J. M.; Zeid, R.; Scott, T. G.; Paulk, J.; Lachance, K.; Olson, C. M.; Dastjerdi, S.; Bauer, S.; Lin, C. Y.; Gray, N. S.; Kelliher, M. A.; Churchman, L. S.; Bradner, J. E. BET Bromodomain Proteins Function as Master Transcription Elongation Factors Independent of CDK9 Recruitment. Mol. Cell 2017, 67 (1), 5-18.

(41) Ycas, P. D.; Zahid, H.; Chan, A.; Olson, N. M.; Johnson, J. A.; Talluri, S. K.; Schonbrunn, E.; Pomerantz, W. C. K. New Inhibitors for the BPTF Bromodomain Enabled by Structural Biology and Biophysical Assay Development. Org. Biomol. Chem. 2020, 18 (27), 5174-5182.

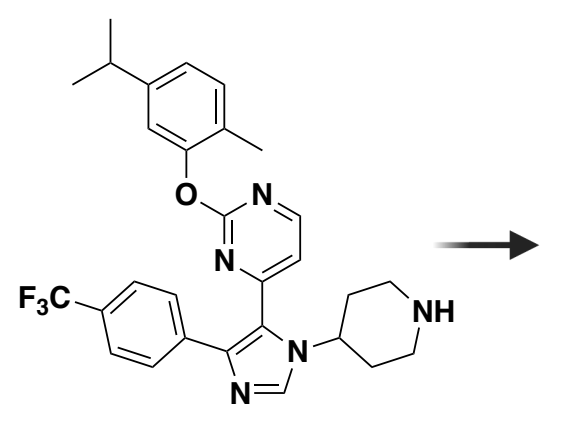

iBRD4-BD1

Selective BRD4-BD1 Inhibitor $\mathrm{IC}_{50}=12 \mathrm{nM}, 23-6200$-fold BET Selectivity

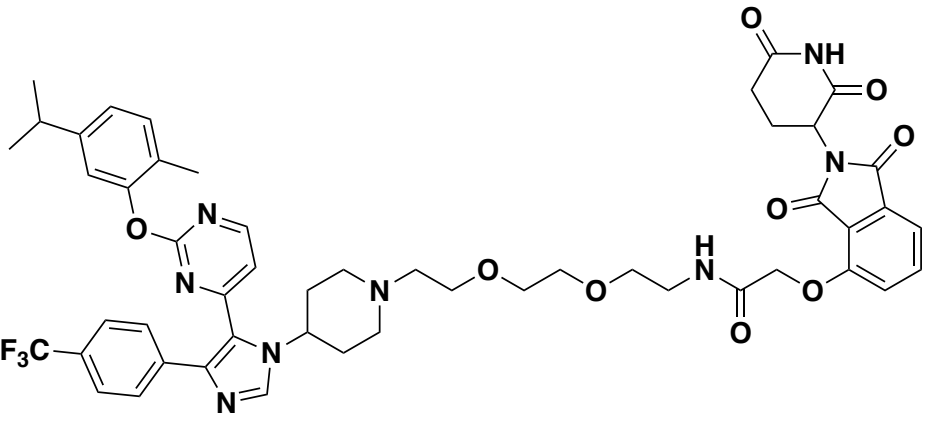

dBRD4-BD1
Selective BRD4 Degrader $\mathrm{DC}_{50}=280 \mathrm{nM}, \mathrm{D}_{\max }=77 \%$

TOC Graphic 


\title{
SUPPORTING INFORMATION FOR:
}

\section{DEVELOPMENT OF AN N-TERMINAL BRD4 BROMODOMAIN-TARGETED DEGRADER}

\author{
Anand Divakaran, ${ }^{\S}$ Huda Zahid, ${ }^{\dagger}$ Wenwei Lin, ${ }^{\dagger}$ Taosheng Chen, ${ }^{\dagger}$ Daniel A. Harki, ${ }^{\S \dagger *}$ and William C.K. Pomerantz ${ }^{\dagger} *$ \\ $\S$ Department of Medicinal Chemistry, University of Minnesota, 2231 6th St SE, Minneapolis, MN 55455, United States \\ + Department of Chemistry, University of Minnesota, 207 Pleasant St. SE, Minneapolis, MN55455, United States \\ $\ddagger$ Department of Chemical Biology and Therapeutics, St. Jude Children's Research Hospital, Memphis, Tennessee 38105, United States
}

\section{METHODS:}

Synthetic Methods: All commercially available chemicals were used without further purification. Flash column chromatography was performed on a Teledyne-Isco Rf-plus CombiFlash instrument with RediSep Gold Silica columns. Spectra were collected on a Bruker Avance III HD 500 or a Bruker Avance III HD 900. Chemical shifts ( $\delta$ ) are reported in parts per million (ppm) and referenced to residual solvent signal, ${ }^{1} \mathrm{H} 7.26 \mathrm{ppm},{ }^{13} \mathrm{C} 77.0 \mathrm{ppm}$ in $\mathrm{CDCl}_{3} ;{ }^{1 \mathrm{H}} 3.32 \mathrm{ppm},{ }^{13} \mathrm{C} 49.2 \mathrm{ppm}$ in $\mathrm{MeOD} ;{ }^{1} \mathrm{H} 2.50 \mathrm{ppm},{ }^{13} \mathrm{C} 39.5 \mathrm{ppm}$ in DMSO-d6. Coupling constants $(J)$ are reported in $\mathrm{Hz}$. Splitting patterns are reported as $\mathrm{s}$ (singlet), $\mathrm{d}$ (doublet), $\mathrm{t}$ (triplet), $\mathrm{q}$ (quartet), $\mathrm{m}$ (multiplet) and br (broad). High resolution mass spectrometry was used with positive-mode electrospray-ionization methods (ESI-MS) using a Bruker BioTOF II. Purities of final compounds were verified by reverse-phase high-performance liquid chromatography (RP-HPLC) with a Zorbax C-18 column across a 10-60\% gradient of $0.1 \%$ TFA water:acetonitrile over 60 min.

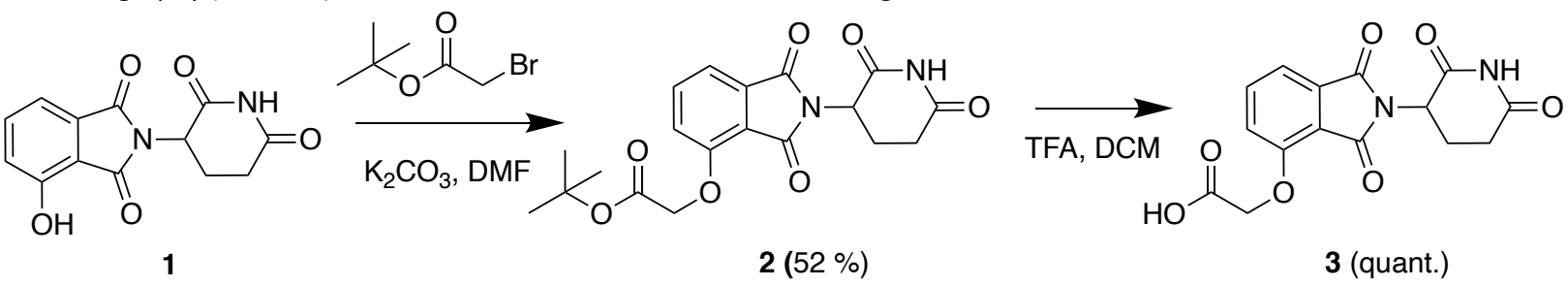

Scheme S1: Synthesis of 2-((2-(2,6-dioxopiperidin-3-yl)-1,3-dioxoisoindolin-4-yl)oxy)acetic acid, (3).

2: In a $10 \mathrm{~mL}$ round-bottomed flask, 1 (120 mg, $0.43 \mathrm{mmol}$ ) was added to dry DMF (1 mL), followed by addition of potassium carbonate (Alfa Aesar, $90 \mathrm{mg}, 0.65 \mathrm{mmol}$ ) and tert-butyl 2-bromoacetate (Sigma, $93 \mathrm{mg}, 0.48 \mathrm{mmol}$ ). The reaction mixture was stirred at room temperature and followed by TLC. After two hours, the reaction was quenched by addition of water (10 $\mathrm{mL}$ ) and the yellow aqueous layer was extracted $3 x$ in ethyl acetate $(10 \mathrm{~mL})$. Longer reaction times can lead to a dialkylated product. The combined organics were extracted over brine and anhydrous magnesium sulfate, concentrated by rotary evaporation, and purified by Combiflash chromatography $(0-100 \%$ hexanes:ethyl acetate) to yield a yellow solid ( $86 \mathrm{mg}, 52 \%) .{ }^{1} \mathrm{H} \mathrm{NMR}(500 \mathrm{MHz}$, Methanol-d4) $\delta 7.8(\mathrm{dd}, \mathrm{J}=8.5,7.3 \mathrm{~Hz}, 1 \mathrm{H}), 7.5(\mathrm{dd}, \mathrm{J}=7.3,0.6 \mathrm{~Hz}, 1 \mathrm{H}), 7.3(\mathrm{~d}, \mathrm{~J}=8.4 \mathrm{~Hz}, 1 \mathrm{H}), 5.1(\mathrm{dd}, \mathrm{J}=12.5,5.5 \mathrm{~Hz}, 1 \mathrm{H}), 4.9(\mathrm{~s}$, $2 \mathrm{H}), 2.9-2.8(\mathrm{~m}, 2 \mathrm{H}), 2.8-2.7(\mathrm{~m}, 2 \mathrm{H}), 2.2-2.1(\mathrm{~m}, 1 \mathrm{H}), 1.5(\mathrm{~s}, 9 \mathrm{H})$. Note: ${ }^{1} \mathrm{H}-\mathrm{NMR}$ contained an ethyl acetate impurity.

3: Compound 2 ( $80 \mathrm{mg}, 0.2 \mathrm{mmol})$ was dissolved in dry DCM $(2 \mathrm{~mL})$ and trifluoracetic acid $(2 \mathrm{~mL})$ was added dropwise while stirring. After stirring at room temperature for 2 hours and confirming completion of reaction progress by TLC, the reaction mix was blown dry under a stream of nitrogen and dried under vacuum. The crude product, 3, was used without further purification.

5: Common intermediate 4 was synthesized as previously described. ${ }^{28}$ In a sealed tube, 4 ( $310 \mathrm{mg}, 0.56 \mathrm{mmol}$ ) was stirred with carvacrol (Sigma, $250 \mathrm{mg}, 1.7 \mathrm{mmol}$ ), potassium carbonate $\left(150 \mathrm{mg}, 1.1 \mathrm{mmol}\right.$ ) and $2 \mathrm{~mL} \mathrm{DMF}$ for $16 \mathrm{~h}$ at $130{ }^{\circ} \mathrm{C}$ behind a blast shield. The reaction mixture was cooled before being quenched in $20 \mathrm{~mL}$ cold water and extracted $3 x$ in $40 \mathrm{~mL}$ ethyl acetate. The combined organics were extracted over brine and anhydrous magnesium sulfate and concentrated by rotary evaporation. The crude brown oil was purified by normal phase Combiflash chromatography (0-100\% hexanes:ethyl acetate) to yield a yellow foam (340 mg, 96\% yield). ${ }^{1} \mathrm{H}$ NMR (400 MHz, Chloroform-d) $\delta 8.4(\mathrm{~d}, \mathrm{~J}=5.1 \mathrm{~Hz}, 1 \mathrm{H}), 7.8(\mathrm{~s}, 1 \mathrm{H}), 7.7-7.5(\mathrm{~m}, 4 \mathrm{H}), 7.2(\mathrm{~d}, \mathrm{~J}=7.8 \mathrm{~Hz}, 2 \mathrm{H})$, $7.1(\mathrm{~d}, \mathrm{~J}=7.8,1.8 \mathrm{~Hz}, 1 \mathrm{H}), 7.1(\mathrm{~d}, \mathrm{~J}=1.8 \mathrm{~Hz}, 1 \mathrm{H}), 6.9(\mathrm{~d}, \mathrm{~J}=5.1 \mathrm{~Hz}, 1 \mathrm{H}), 4.7-4.6(\mathrm{~m}, 1 \mathrm{H}), 4.1(\mathrm{q}, \mathrm{J}=7.1 \mathrm{~Hz}, 2 \mathrm{H}), 3.0-2.9(\mathrm{~m}, 1 \mathrm{H})$, $2.5(\mathrm{t}, \mathrm{J}=12.8 \mathrm{~Hz}, 2 \mathrm{H}), 2.2(\mathrm{~s}, 3 \mathrm{H}), 2.1(\mathrm{~s}, 1 \mathrm{H}), 2.0-1.9(\mathrm{~m}, 2 \mathrm{H}), 1.8-1.7(\mathrm{~m}, 3 \mathrm{H}), 1.5(\mathrm{~s}, 9 \mathrm{H}), 1.3(\mathrm{~d}, \mathrm{~J}=6.9 \mathrm{~Hz}, 7 \mathrm{H}) .{ }^{13} \mathrm{C}-\left\{{ }^{1} \mathrm{H},{ }^{19} \mathrm{~F}\right\}$ 
NMR (101 MHz, Chloroform-d) $\delta 165.1,160.2,159.8,154.4,151.2,148.4,137.9,136.8,131.2,128.8,127.5,125.6,125.6,125.5$, 124.0, 120.2, 116.3, 80.1, 54.1, 33.6, 28.4, 23.9, 16.2. ${ }^{19} \mathrm{~F}$ NMR (471 MHz, Chloroform-d) $\delta$-64.1.

6 (iBRD4-BD1): 2 (310 mg, $0.50 \mathrm{mmol}$ ) was dissolved in DCM $(5 \mathrm{~mL})$ and TFA (1 mL) was added dropwise while stirring. The reaction mix was stirred overnight at room temperature and blown dry under a stream of nitrogen before being dried under vacuum. The crude material was triturated in cold diethyl ether to yield a fine white powder that was used without further purification ( $313 \mathrm{mg}, 83 \%$ yield). ${ }^{1} \mathrm{H}$ NMR $\left(500 \mathrm{MHz}\right.$, Methanol- $\left.d_{4}\right) \delta 8.5(\mathrm{~d}, J=5.0,1.5 \mathrm{~Hz}, 1 \mathrm{H}), 8.2(\mathrm{~s}, 1 \mathrm{H}), 7.7(\mathrm{~d}, J=8.1 \mathrm{~Hz}, 2 \mathrm{H})$, $7.6(\mathrm{~d}, J=8.0 \mathrm{~Hz}, 2 \mathrm{H}), 7.3(\mathrm{~d}, J=7.7 \mathrm{~Hz}, 1 \mathrm{H}), 7.1(\mathrm{~d}, J=7.8 \mathrm{~Hz}, 2 \mathrm{H}), 7.0(\mathrm{~d}, J=5.2 \mathrm{~Hz}, 1 \mathrm{H}), 4.7(\mathrm{dt}, J=12.1,4.0 \mathrm{~Hz}, 1 \mathrm{H}), 3.5(\mathrm{q}, J=$ $7.1 \mathrm{~Hz}, 2 \mathrm{H}), 2.9(\mathrm{p}, J=6.9 \mathrm{~Hz}, 1 \mathrm{H}), 2.8(\mathrm{dt}, J=12.4 \mathrm{~Hz}, 2 \mathrm{H}), 2.2(\mathrm{~s}, 3 \mathrm{H}), 2.1(\mathrm{qd}, J=13.1,4.0 \mathrm{~Hz}, 2 \mathrm{H}), 1.3(\mathrm{~d}, J=7.1,1.5 \mathrm{~Hz}, 6 \mathrm{H}), 1.2$ $(t, J=7.0,1.5 \mathrm{~Hz}, 3 \mathrm{H}) .{ }^{13} \mathrm{C}-\left\{{ }^{1} \mathrm{H},{ }^{19} \mathrm{~F}\right\}$ NMR $\left(126 \mathrm{MHz}\right.$, Methanol- $\left.\mathrm{d}_{4}\right) \delta 164.9,160.6,158.6,151.2,148.6,137.0,136.4,131.1,129.0$, $127.2,125.5,123.6,120.0,116.8,51.7,43.3,33.4,29.6,23.0,14.8 .{ }^{19} \mathrm{~F} \mathrm{NMR}\left(471 \mathrm{MHz}\right.$, Methanol- $\left.d_{4}\right) \delta-64.2,-75.8(2 x T F A ~ s a l t)$. HRMS (ESI-TOF) $\mathrm{m} / \mathrm{z}[\mathrm{M}+\mathrm{H}]+$ calcd. for $\mathrm{C}_{29} \mathrm{H}_{31} \mathrm{~F}_{3} \mathrm{~N}_{5} \mathrm{O}$ 522.2480, found 522.2443. Purity: 95.5\%.<smiles>Cc1ccc(C(C)C)cc1Oc1nccc(-c2ncn(C3CCNCC3)c2-c2ccc(C(F)(F)F)cc2)n1</smiles>

4

$5(96 \%)$

6, iBRD4-BD1 (83\%)

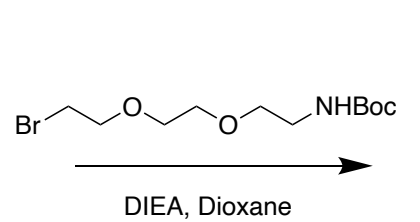<smiles>Cc1ccc(-c2ncn(C3CCN(CCOCCOCCNC(=O)OC(C)(C)C)CC3)c2-c2ccnc(Oc3cc(C(C)C)ccc3C)n2)cc1</smiles>

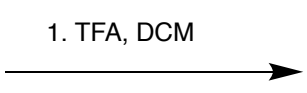

2. 3, HCTU, DIEA<smiles>Cc1ccc(C(C)C)cc1Oc1cnc(-c2c(-c3ccc(C(F)(F)F)cc3)ncn2C2CCN(CCOCCOCCNC(=O)COc3cccc4c3C(=O)N(C3CCC(=O)NC3=O)C4=O)CC2)cn1</smiles>

Scheme S2: Synthesis of degrader dBRD4-BD1.

7: In a sealed tube, 6 (55 mg, $0.1 \mathrm{mmol})$ was stirred with tert-butyl 3-(2-(2-bromoethoxy)ethoxy)propanoate (PurePEG, $49 \mathrm{mg}$, $0.2 \mathrm{mmol}$ ), DIEA ( $27 \mathrm{mg}, 0.2 \mathrm{mmol}$ ) and $1 \mathrm{~mL}$ 1,4-dioxane for $16 \mathrm{~h}$ at $120^{\circ} \mathrm{C}$ behind a blast shield. The reaction mixture was cooled before being quenched in $10 \mathrm{~mL}$ of cold water and extracted $3 x$ in $10 \mathrm{~mL}$ ethyl acetate. The combined organics were dried over anhydrous magnesium sulfate and concentrated by rotary evaporation. The crude orange oil was purified by Combiflash chromatography (0-25\% DCM:methanol) to yield an off-white powder (13 mg, 17\% yield). ${ }^{1} \mathrm{H}$ NMR (500 MHz, DMSO-d6) $\delta 8.6$ (d, $\mathrm{J}=5.0 \mathrm{~Hz}, 1 \mathrm{H}), 8.2(\mathrm{~s}, 1 \mathrm{H}), 7.7(\mathrm{~d}, \mathrm{~J}=8.2 \mathrm{~Hz}, 2 \mathrm{H}), 7.6(\mathrm{~d}, \mathrm{~J}=8.1 \mathrm{~Hz}, 2 \mathrm{H}), 7.2(\mathrm{~d}, \mathrm{~J}=8.3 \mathrm{~Hz}, 1 \mathrm{H}), 7.1(\mathrm{~d}, \mathrm{~J}=5.1 \mathrm{~Hz}, 1 \mathrm{H}), 7.1(\mathrm{dd}, \mathrm{J}=$ $5.8,2.0 \mathrm{~Hz}, 2 \mathrm{H}), 6.7(\mathrm{t}, \mathrm{J}=5.8 \mathrm{~Hz}, 1 \mathrm{H}), 4.2-4.1(\mathrm{~m}, 2 \mathrm{H}), 3.5(\mathrm{~s}, 6 \mathrm{H}), 3.4(\mathrm{t}, \mathrm{J}=6.2 \mathrm{~Hz}, 4 \mathrm{H}), 3.2(\mathrm{~d}, \mathrm{~J}=3.4 \mathrm{~Hz}, 3 \mathrm{H}), 3.1(\mathrm{q}, \mathrm{J}=6.0 \mathrm{~Hz}$, $2 \mathrm{H}), 2.9-2.8(\mathrm{~m}, 3 \mathrm{H}), 2.1(\mathrm{~s}, 3 \mathrm{H}), 1.9-1.8(\mathrm{~m}, 4 \mathrm{H}), 1.7(\mathrm{dd}, \mathrm{J}=9.0,4.7 \mathrm{~Hz}, 2 \mathrm{H}), 1.4(\mathrm{~s}, 9 \mathrm{H}), 1.2(\mathrm{~d}, \mathrm{~J}=6.9 \mathrm{~Hz}, 6 \mathrm{H})-\mathrm{Note}:{ }^{1} \mathrm{H}-\mathrm{NMR}$ contained a minor dioxane impurity @ 3.5 ppm. ${ }^{13} \mathrm{C}-\left\{{ }^{1} \mathrm{H},{ }^{19} \mathrm{~F}\right\}$ NMR $(126 \mathrm{MHz}$, DMSO-d6) $\delta$ 165.2, 161.6, 159.9, 151.4, 148.3, 140.4, 
138.7, 138.2, 131.6, 128.5, 127.3, 125.8, 125.5, 123.8, 120.5, 117.8, 70.1, 69.9, 69.6, 69.0, 57.3, 54.0, 53.1, 33.3, 33.0, 29.5, 28.7, 24.2, 16.2. ${ }^{19} \mathrm{~F}$ NMR (471 MHz, DMSO-d6) $\delta$-60.9. HRMS (ESI-TOF) $\mathrm{m} / \mathrm{z}[\mathrm{M}+\mathrm{H}]+$ calcd. for $\mathrm{C}_{40} \mathrm{H}_{52} \mathrm{~F}_{3} \mathrm{~N}_{6} \mathrm{O}_{5} 753.3951$, found 753.4131 .

8 (dBRD4-BD1): 7 (11 mg, $15 \mu \mathrm{mol}$ ) was dissolved in $2 \mathrm{M}$. $\mathrm{HCl}$ in dioxane $(2 \mathrm{~mL}$ ) and stirred for $16 \mathrm{~h}$ at room temperature. The reaction mixture was dried under a stream of nitrogen and dried further under vacuum. The crude material was dissolved in dry $\operatorname{DMF}(900 \mu \mathrm{L})$ and DIEA $(7.5 \mathrm{mg}, 60 \mu \mathrm{mol})$ was added while stirring. A mixture of acid $3(10 \mathrm{mg}, 30 \mu \mathrm{mol})$ and HCTU (12 mg, 30 $\mu \mathrm{mol})$ was subsequently added in dry DMF $(100 \mu \mathrm{L})$ and the reaction mixture was stirred for $2 \mathrm{~h}$ at room temperature. The crude material was purified by preparative HPLC (10-75\% gradient in $0.1 \%$ aqueous TFA:acetonitrile) to yield the desired product. $1 \mathrm{H}$ $\operatorname{NMR}\left(900 \mathrm{MHz}, \mathrm{DMSO}-\mathrm{d}_{6}\right) \delta 11.1(\mathrm{~s}, 1 \mathrm{H}), 8.7(\mathrm{~d}, \mathrm{~J}=5.0 \mathrm{~Hz}, 1 \mathrm{H}), 8.1(\mathrm{~s}, 1 \mathrm{H}), 8.0(\mathrm{t}, \mathrm{J}=5.7 \mathrm{~Hz}, 1 \mathrm{H}), 7.8(\mathrm{t}, \mathrm{J}=8.1,7.6 \mathrm{~Hz}, 1 \mathrm{H}), 7.7(\mathrm{~d}$, $J=8.0 \mathrm{~Hz}, 2 \mathrm{H}), 7.6(\mathrm{~d}, \mathrm{~J}=8.0 \mathrm{~Hz}, 2 \mathrm{H}), 7.5(\mathrm{~d}, \mathrm{~J}=7.2 \mathrm{~Hz}, 1 \mathrm{H}), 7.4(\mathrm{~d}, \mathrm{~J}=8.6 \mathrm{~Hz}, 1 \mathrm{H}), 7.2(\mathrm{~d}, \mathrm{~J}=7.9 \mathrm{~Hz}, 1 \mathrm{H}), 7.2(\mathrm{~d}, \mathrm{~J}=5.0 \mathrm{~Hz}, 1 \mathrm{H}), 7.1$ $(\mathrm{d}, \mathrm{J}=8.8 \mathrm{~Hz}, 2 \mathrm{H}), 5.1(\mathrm{dd}, \mathrm{J}=13.0,5.5 \mathrm{~Hz}, 1 \mathrm{H}), 4.8(\mathrm{~s}, 2 \mathrm{H}), 4.4(\mathrm{~m}, \mathrm{~J}=12.0,7.8,4.7,4.1 \mathrm{~Hz}, 1 \mathrm{H}), 3.8(\mathrm{t}, \mathrm{J}=4.9 \mathrm{~Hz}, 3 \mathrm{H}), 3.6(\mathrm{dd}, \mathrm{J}=$ $6.0,3.4 \mathrm{~Hz}, 4 \mathrm{H}), 3.6(\mathrm{dd}, \mathrm{J}=6.0,3.2 \mathrm{~Hz}, 4 \mathrm{H}), 3.5(\mathrm{t}, \mathrm{J}=5.7 \mathrm{~Hz}, 4 \mathrm{H}), 3.3(\mathrm{q}, \mathrm{J}=5.7 \mathrm{~Hz}, 3 \mathrm{H}), 3.3-3.3(\mathrm{~m}, 2 \mathrm{H}), 3.2(\mathrm{~s}, 1 \mathrm{H}), 3.1-3.1(\mathrm{~m}$, $1 \mathrm{H}), 2.9-2.9(\mathrm{~m}, 3 \mathrm{H}), 2.8(\mathrm{~h}, \mathrm{~J}=6.9 \mathrm{~Hz}, 1 \mathrm{H}), 2.6(\mathrm{dt}, \mathrm{J}=17.0,3.5 \mathrm{~Hz}, 1 \mathrm{H}), 2.2-2.2(\mathrm{~m}, 2 \mathrm{H}), 2.1-2.0(\mathrm{~m}, 1 \mathrm{H}), 1.9-1.9(\mathrm{~m}, 1 \mathrm{H}), 1.2$ $(\mathrm{s}, 3 \mathrm{H}), 1.1(\mathrm{~d}, \mathrm{~J}=7.0 \mathrm{~Hz}, 6 \mathrm{H})$ - Note: ${ }^{1} \mathrm{H}-\mathrm{NMR}$ contained an acetone impurity @ $2.1 \mathrm{ppm} .{ }^{13} \mathrm{C}-\left\{{ }^{1} \mathrm{H},{ }^{19} \mathrm{~F}\right\} \mathrm{NMR}\left(226 \mathrm{MHz}, \mathrm{DMSO}-\mathrm{d}_{6}\right) \delta$ $173.3,170.4,167.4,167.2,166.0,165.2,161.7,159.6,158.3,155.4,151.4,148.3,140.2,138.4,137.4,133.5,131.5,128.4,127.4$, 125.9, 123.8, 120.9, 120.5, 118.0, 117.3, 116.6, 70.1, 69.8, 69.2, 68.0, 64.8, 55.8, 51.8, 51.0, 49.3, 40.7, 40.4, 39.3, 39.2, 39.1, 38.8, 33.3, 31.4, 31.2, 30.3, 29.5, 24.2, 22.5, 16.1. ${ }^{19} \mathrm{~F}$ NMR (471 MHz, Chloroform-d) $\delta-62.8,-75.8$ (3xTFA salt). HRMS (ESI-TOF) $\mathrm{m} / \mathrm{z}[\mathrm{M}+\mathrm{H}]+$ calcd. for $\mathrm{C}_{50} \mathrm{H}_{54} \mathrm{~F}_{3} \mathrm{~N}_{8} \mathrm{O}_{9} 967.3965$, found 967.3900. Purity: $97.1 \%$

General procedure for AlphaScreen: Unlabeled His9-tagged BRD4-BD1 was expressed and purified as described previously. ${ }^{41}$ The AlphaScreen assay procedure for BRD4-BD1 bromodomain was adapted from the manufacturers protocol (PerkinElmer, USA). Nickel chelate (Ni-NTA) acceptor beads and streptavidin donor beads were purchased from PerkinElmer (Cat. \#: 6760619M). The biotinylated histone $\mathrm{H} 4 \mathrm{KAc5}, 8,12,16$ peptide was purchased from EpiCypher, with the sequence: AcSGRGK(Ac)GGK(Ac)GLGK(Ac)GGAK(Ac)RHRKVLR-Peg-(Biot). All reagents were diluted in the assay buffer (50 mM HEPES-Na+ (Chemlmpex), $100 \mathrm{mM} \mathrm{NaCl}$ (SigmaAldrich), 0.05\% CHAPS (RPI), 0.1\% BSA (SigmaAldrich), pH 7.4). The final assay concentrations (after the addition of all assay components) of $30 \mathrm{nM}$ for His -tagged BRD4-BD1 bromodomain and $50 \mathrm{nM}$ for the biotinylated peptide were used. Three-fold serial dilutions were prepared with varying concentrations of the compounds and a fixed protein concentration, keeping the final DMSO concentration at $1 \% \mathrm{v} / \mathrm{v} .5 \mu \mathrm{L}$ of these solutions were added to a 384-well plate (ProxiPlate-384, PerkinElmer). This was followed by the addition of $5 \mu \mathrm{L}$ of the biotinylated peptide. $5 \mu \mathrm{L}$ of nickel chelate acceptor beads and $5 \mu \mathrm{L}$ of streptavidin donor beads were added to each well under low light conditions ( $<100$ lux), to a final concentration of $20 \mu \mathrm{g} / \mathrm{mL}$. The plate was sealed and incubated at room temperature in the dark for $1 \mathrm{~h}$. It was then read in AlphaScreen mode using a Tecan Spark plate reader. Each compound was run in two technical replicates, with at least three biological replicates. The data was normalized against $1 \%$ DMSO $\left(0 \mu \mathrm{M}\right.$ inhibitor) signal and $\mathrm{IC}_{50}$ values were calculated in GraphPad Prism 5 using sigmoidal 4-parameter logistic (4PL) curve fit.

BET Alphascreen was performed at Reaction Biology corp. (Malvern, PA) in duplicate 10-point dose-response format, with a topconcentration of $100 \mu \mathrm{M}$ and 3-fold dilutions.

General procedure for TR-FRET: Ternary complex formation assays were performed among GST-BRD4-BD1 (or GST-BRD4-BD2), ligand and His-CRBN. The GST-BRD4-BD1 and GST-BRD4-BD2 were obtained from BPS Bioscience (San Diego, CA). His-CRBN [HisCRBN(DDB1)] was prepared by the Protein Production Facility at St. Jude Children's Research Hospital. Tb-anti-GST antibody, AF488-anti-His antibody, Tris (pH 7.5, $1 \mathrm{M})$, DTT (1 M) and DMSO were purchased from Fisher Scientific (Pittsburgh, PA). dBET1 was purchased from MedChemExpress USA (Monmouth Junction, NJ). Bovine serum albumin and Triton X-100 were obtained from Sigma (St. Louis, MO). Black, low volume 384-well assay plates were purchased from Corning Incorporated Life Sciences (Tewksbury, MA). The TR-FRET ternary complex formation assay buffer (TR-FRET buffer) was formulated with $50 \mathrm{mM}$ Tris (pH 7.5), $0.01 \%$ Triton X-100, $0.01 \%$ bovine serum albumin, $1 \mathrm{mM} \mathrm{DTT}$ and was freshly prepared before each experiment. All chemicals were solubilized in DMSO as $10 \mathrm{mM}$ stocks. Chemical DMSO stocks were dispensed with an Echo 555 acoustic liquid handler (Labcyte Inc., San Jose, CA) to give the final indicated concentrations with the final DMSO concentration at $1 \%$ for all assay wells. The reported optimized TR-FRET ternary complex formation assay condition (condition 5) for BRD, PROTAC and CRBN protein was followed. ${ }^{35}$ Briefly, dilutions of dBET1, dBRD4-BD1, iBRD4-BD1 or 4-OH-Thalidomide were first incubated with a protein mixture (10 $\mu \mathrm{L} /$ well) of $4 \mathrm{nM}$ Tb-anti-GST and $4 \mathrm{nM} \mathrm{GST-BRD4-BD1} \mathrm{(or} \mathrm{GST-BRD4-BD2)} \mathrm{for} 30 \mathrm{~min}$. A mixture (10 $\mu \mathrm{L} /$ well) of 16 $\mathrm{nM}$ His-CRBN and $8 \mathrm{nM}$ AF488-anti-His was then dispensed and the assay plate was incubation for 180 min before the TR-FRET signal $(10000 \times 520 \mathrm{~nm} / 490 \mathrm{~nm})$ from each well was measured with a PHERAstar FS plate reader (BMG Labtech; Durham, NC). The final respective Tb-anti-GST, GST-BRD4-BD1 (or GST-BRD4-BD2), His-CRBN and AF488-anti-His were 2, 2, 8 and 4 nM. The final dBET1 concentration range tested was from $30 \mu \mathrm{M}$ to $0.17 \mathrm{nM}$ in a 1-to-3 dilution pattern. The final dBRD4-BD1, iBRD4-BD1 or 4-OH-Thalidomide concentration range tested was from $10 \mu \mathrm{M}$ to $0.17 \mathrm{nM}$ in a 1-to-3 dilution pattern. In addition, a group of wells with $1 \%$ DMSO and protein components were also included in each plate to serve as the negative control group. The TR- 
FRET Signal Fold-to-DMSO was calculated by dividing the TR-FRET signal of a tested ligand at its specific concentration by that of DMSO. The TR-FRET Signal Fold-to-DMSO for each chemical at its specific concentration was plotted with GraphPad PRISM to derive the dose response curve for each ligand. The TR-FRET ternary complex formation assays were performed three times in quadruplicate.

Cell Culture: MM.1S cells were grown in a humidified $5 \% \mathrm{CO}_{2}$ environment at $37^{\circ} \mathrm{C}$. Cells were cultured in RPMI 1640 media (Corning) supplemented with $10 \%$ fetal-bovine serum (FBS, Cellgro), penicillin ( $50 \mathrm{IU} / \mathrm{mL}$, Cellgro) and streptomycin ( $50 \mu \mathrm{g} / \mathrm{mL}$, Cellgro). The mixed suspension/adherent cells were subcultured at a 1:10 dilution by decanting suspended cells and dissociating adherent cells from plates in $0.25 \%$ trypsin/ EDTA (Gibco) with 2 min incubation times. Cell-line authenticity was verified using the short-tandem-repeat (STR)-profiling service provided by ATCC.

CETSA: Approximately $4 \times 10^{6} \mathrm{MM} .1 \mathrm{~S}$ cells were treated with the desired amounts of compound in serum supplemented RPMI1640 media, with DMSO concentrations normalized to $0.05 \%$ for all samples. Dosed cells in microcentrifuge tubes were incubated at $37^{\circ} \mathrm{C}$ for $1 \mathrm{~h}$. with mild intermittent agitation. Upon completion of the incubation period, cells were pelleted at $300 \mathrm{Xg}$. and rinsed in PBS, before being re-suspended in $100 \mu \mathrm{L}$ PBS. Re-suspended cells were thermally denatured at $48^{\circ} \mathrm{C}$ for 3 min in a heat block and subsequently equilibrated at room temperature for a further $3 \mathrm{~min}$. Cells were pelleted at $300 \mathrm{Xg}$., PBS decanted, and resuspended in PBS supplemented with $1 \times$ cOmplete Mini Protease (Roche) before being lysed over three freeze thaw cycles and centrifuged ( $15 \mathrm{~min}$ at $15,000 \mathrm{Xg}$.). Soluble protein concentrations of supernatants were determined using the BCA protein assay kit (Pierce). Samples were normalized to the lowest total soluble-protein concentration and analyzed by western blot.

Western Blotting: MM.1S cells were seeded in 12-well plates at a density of $4 \times 10^{6}$ cells per well and treated with compounds for indicated times. Cells were transferred to $2 \mathrm{~mL}$ microcentrifuge tubes and harvested by low-speed centrifugation at $500 \mathrm{X}$. for $5 \mathrm{~min}$. The well was rinsed, and the cell pellet washed twice with ice-cold PBS with centrifuging. The supernatant was carefully decanted, and the cell pellet was resuspended for lysis in $100 \mu \mathrm{L}$ of RIPA buffer (ThermoFisher Scientific) supplemented with $1 \times$ cOmplete Mini Protease (Roche) and stored on ice for $10 \mathrm{~min}$. After high-speed centrifugation (10 min at 10,000 X g.), protein concentrations were determined by the BCA assay (ThermoFisher Scientific) and normalized by total protein content. Normalized samples were mixed with $4 \times$ NuPAGE LDS loading buffer (Invitrogen) and 10x reducing agent (Invitrogen), and heated at $95^{\circ} \mathrm{C}$ for 10 minutes before separation on 3-8\% Tris-Acetate gels. Proteins were transferred to PVDF membranes for 12 minutes on a BioRad Trans-Blot Turbo. Membranes were dried, blocked in TBS-T containing 5\% nonfat dry milk, and subsequently incubated with TBS-T containing $5 \%$ nonfat dry milk for $4 \mathrm{~h}$ at room temperature, or $16 \mathrm{~h}$ at $4{ }^{\circ} \mathrm{C}$, with primary antibodies at dilutions listed below. After the membranes were washed five times with TBS-T, they were incubated with secondary antibodies for $2 \mathrm{~h}$. at room temperature. Membranes were washed five times in TBS-T and treated with SuperSignal West Dura substrates (Thermo) for 1 min and imaged using a LiCor Odyssey Fc.

Antibodies Used:

\begin{tabular}{|l|l|l|l|l|l|}
\hline Target & Species & Manufacturer & Product No & Dilution & Conjugate \\
\hline BRD4 & Rabbit & CST & E2A7X & $1: 1000$ & \\
\hline BRD3 & Rabbit & Bethyl & BLR069G & $1: 1000$ & \\
\hline BRD2 & Rabbit & Bethyl & BL167-2A2 & $1: 1000$ & \\
\hline cMyc & Rabbit & CST & D84C12 & $1: 750$ & \\
\hline p38 $\alpha$ & Rabbit & CST & $9212 S$ & $1: 1500$ & \\
\hline$\beta$-actin & Mouse & Invitrogen & Actn05(C4) & $1: 2000$ & \\
\hline Vinculin & Mouse & Thermo & $14-9777-82$ & $1: 2000$ & \\
\hline Tubulin & Mouse & Thermo & $236-10501$ & $1: 2000$ & \\
\hline Rabbit & Goat & Invitrogen & G-31460 & $1: 1000$ & HRP \\
\hline Mouse & Goat & Initrogen & G-21040 & $1: 2000$ & HRP \\
\hline Mouse & Goat & Invitrogen & A32729 & $1: 1000$ & Alexa-680 \\
\hline
\end{tabular}

Viability Assays: MM.1S cells were seeded in 96-well plates at approximately 20000 cells per well $(0.05 \mathrm{~mL})$ and dosed with increasing compound concentrations in the presence of $0.05 \%$ DMSO with three technical replicates per concentration. After incubation for $69 \mathrm{~h}$ at $37^{\circ} \mathrm{C}, 10 \mu \mathrm{L}$ of the Alamar Blue reagent (Invitrogen) was added to each well and the plates were incubated for $3 \mathrm{~h}$ at $37^{\circ} \mathrm{C}$. Fluorescence was determined using a Synergy plate reader (BioTek, Ex.: $560 \mathrm{~nm}, \mathrm{Em} .: 590 \mathrm{~nm}$ ) and dose-response data were normalized to untreated and blank wells containing $0.05 \%$ DMSO in cell culture media. Data analysis was performed using GraphPad Prism. 


\section{SUPPLEMENTARY FIGURES}

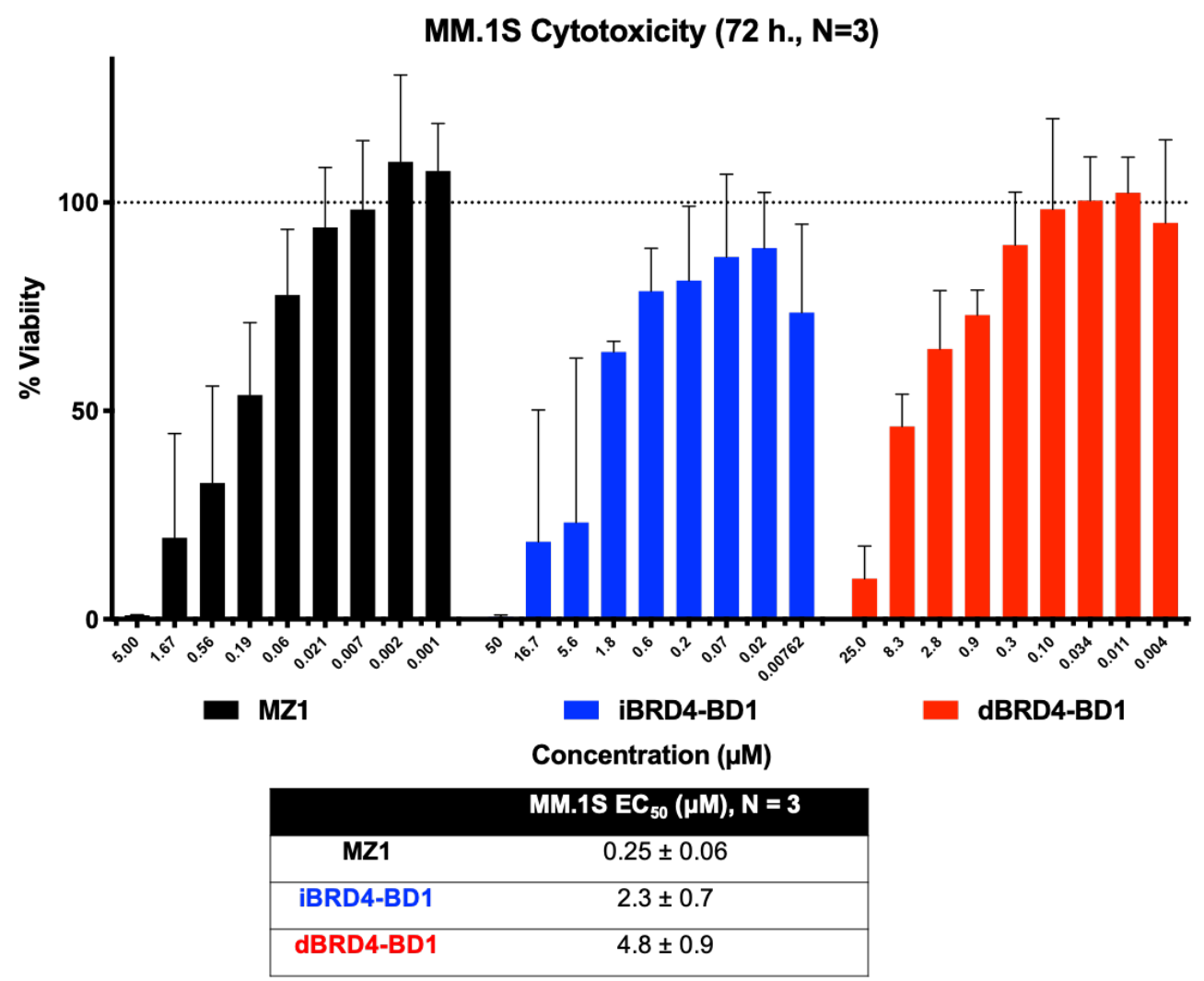

Figure S1: $72 \mathrm{~h}$. Alamar blue cytotoxicity assay of MM.1S cells with compounds. Data reported as mean \pm SD of three independent trials of three replicates each. 


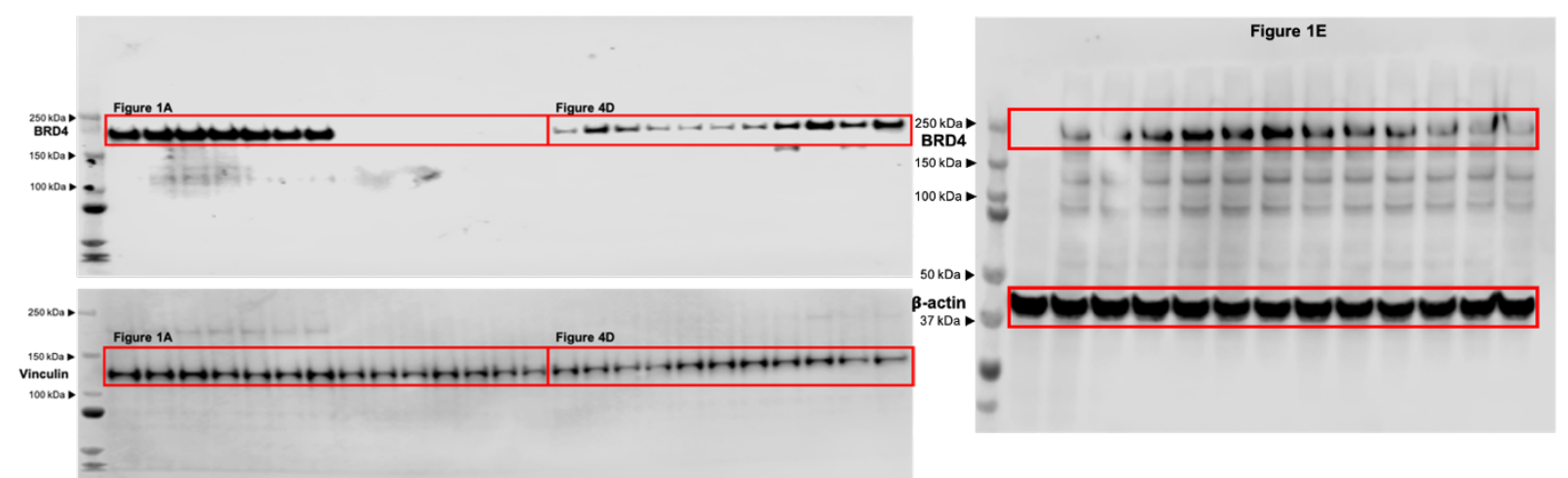

Figure 4A

Figure 4C

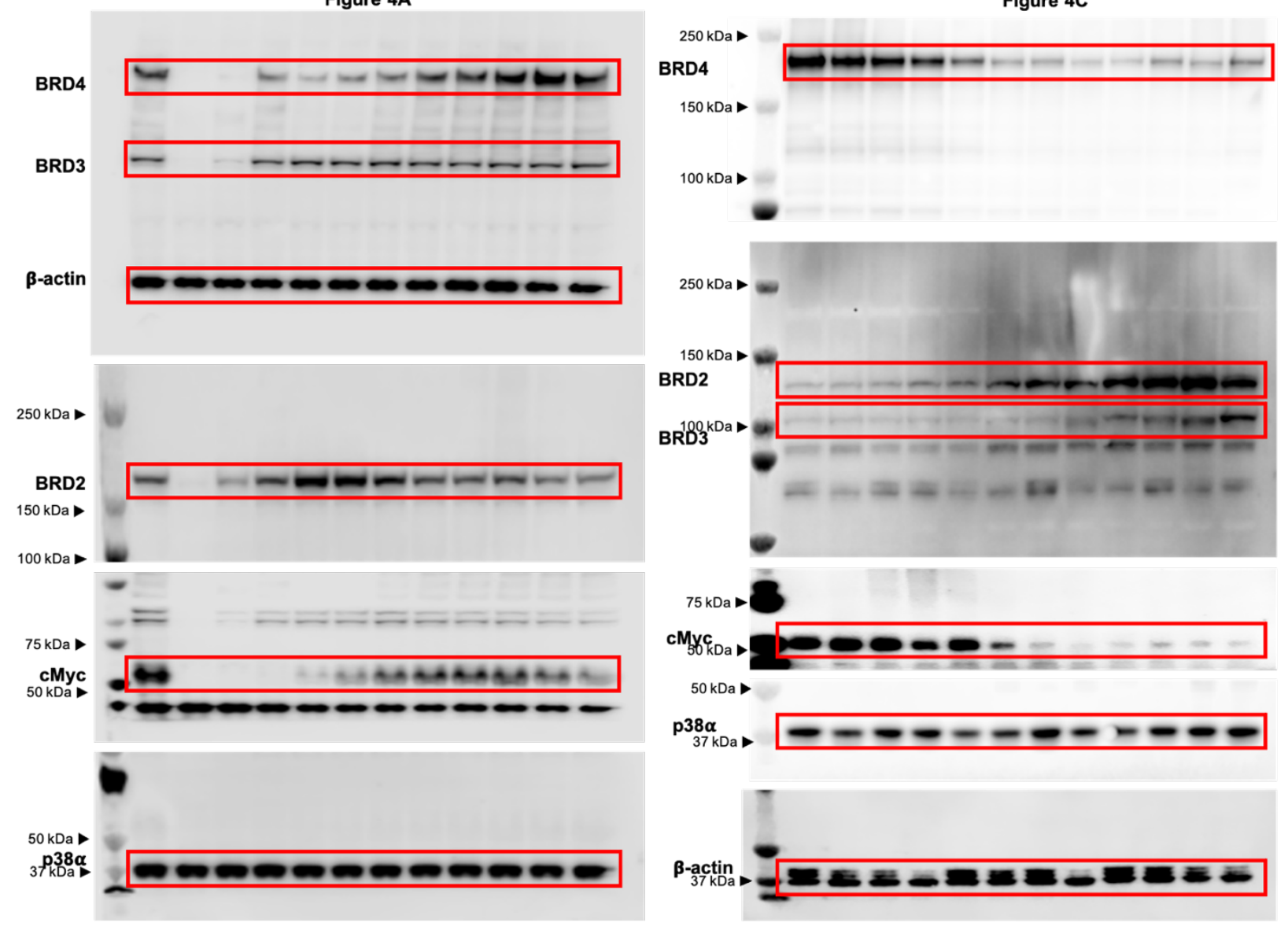

Figure S2: Full images of western blots. 


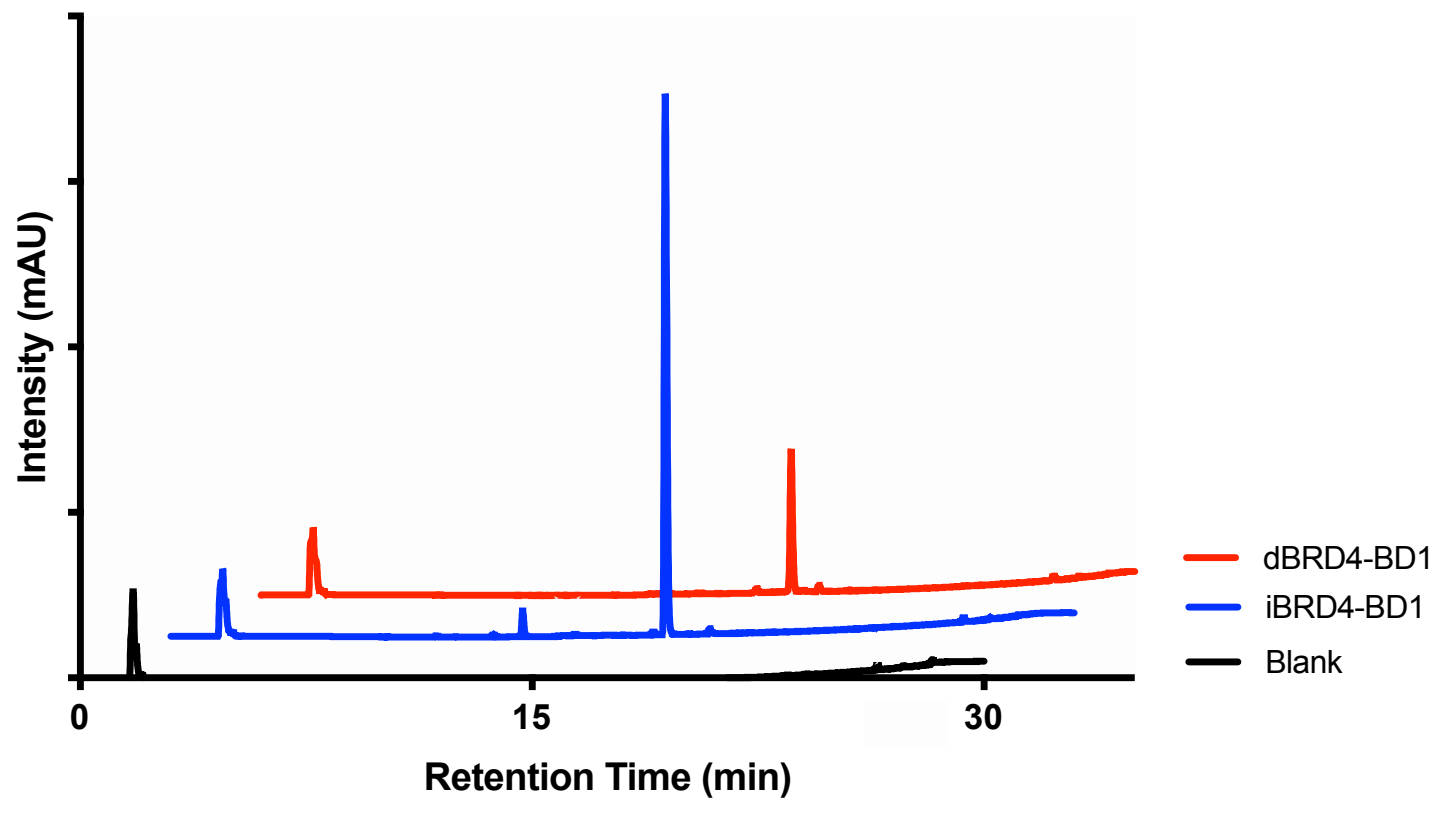

Figure S2: HPLC purity analysis of compounds.

NMR SPECTRA OF SYNTHESIZED COMPOUNDS: 


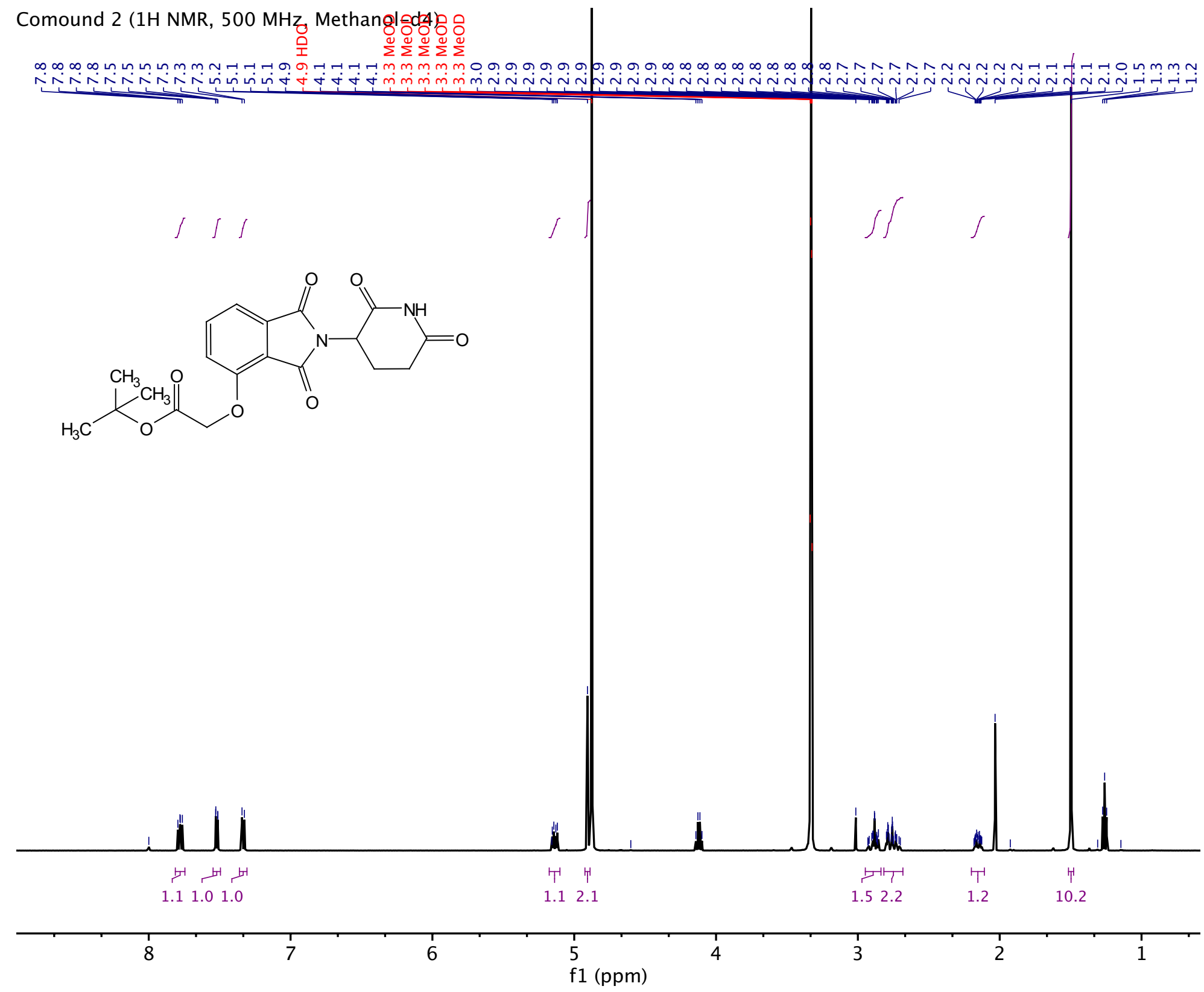


Compound 5 (1H NMR, $400 \mathrm{MHz}$, Chloroform-d)

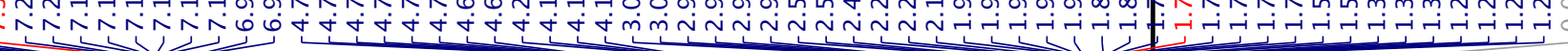
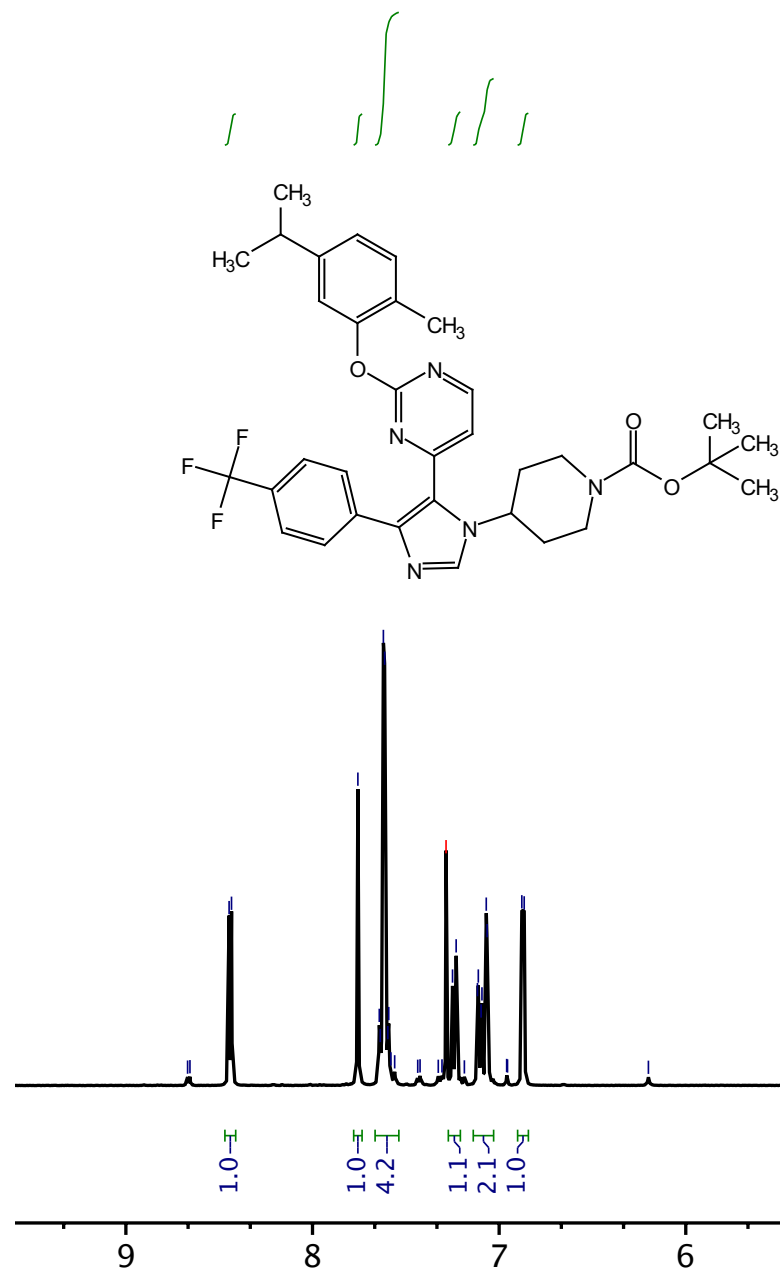

8

7

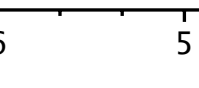

f1 (ppm)

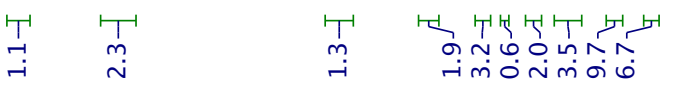

2

1 
Compound 5 (13C NMR, $101 \mathrm{MHz}$, Chloroform-d)

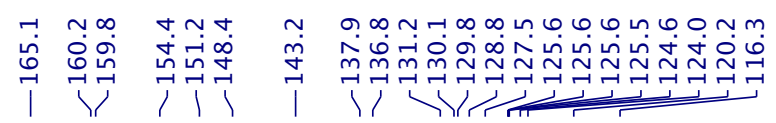

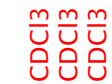

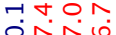

成会

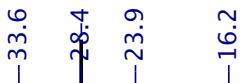
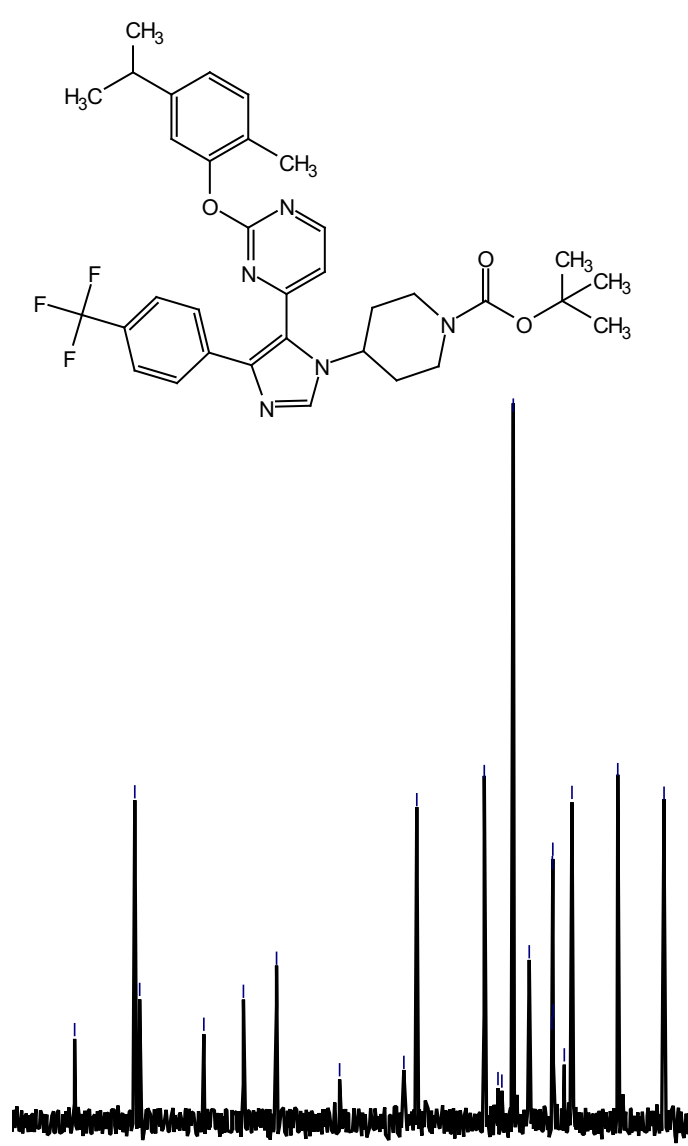

$70 \quad 160 \quad 150$ 140 


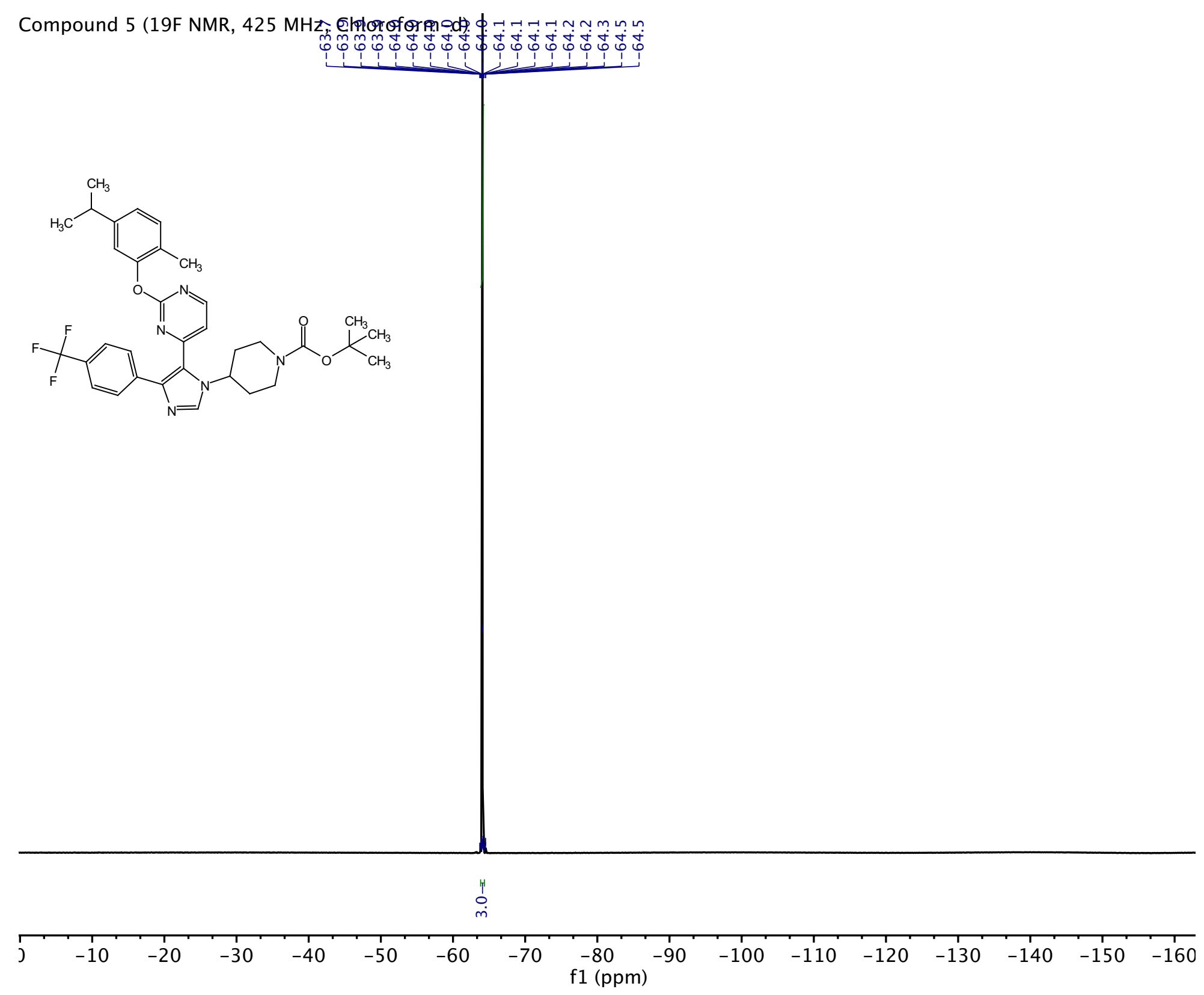




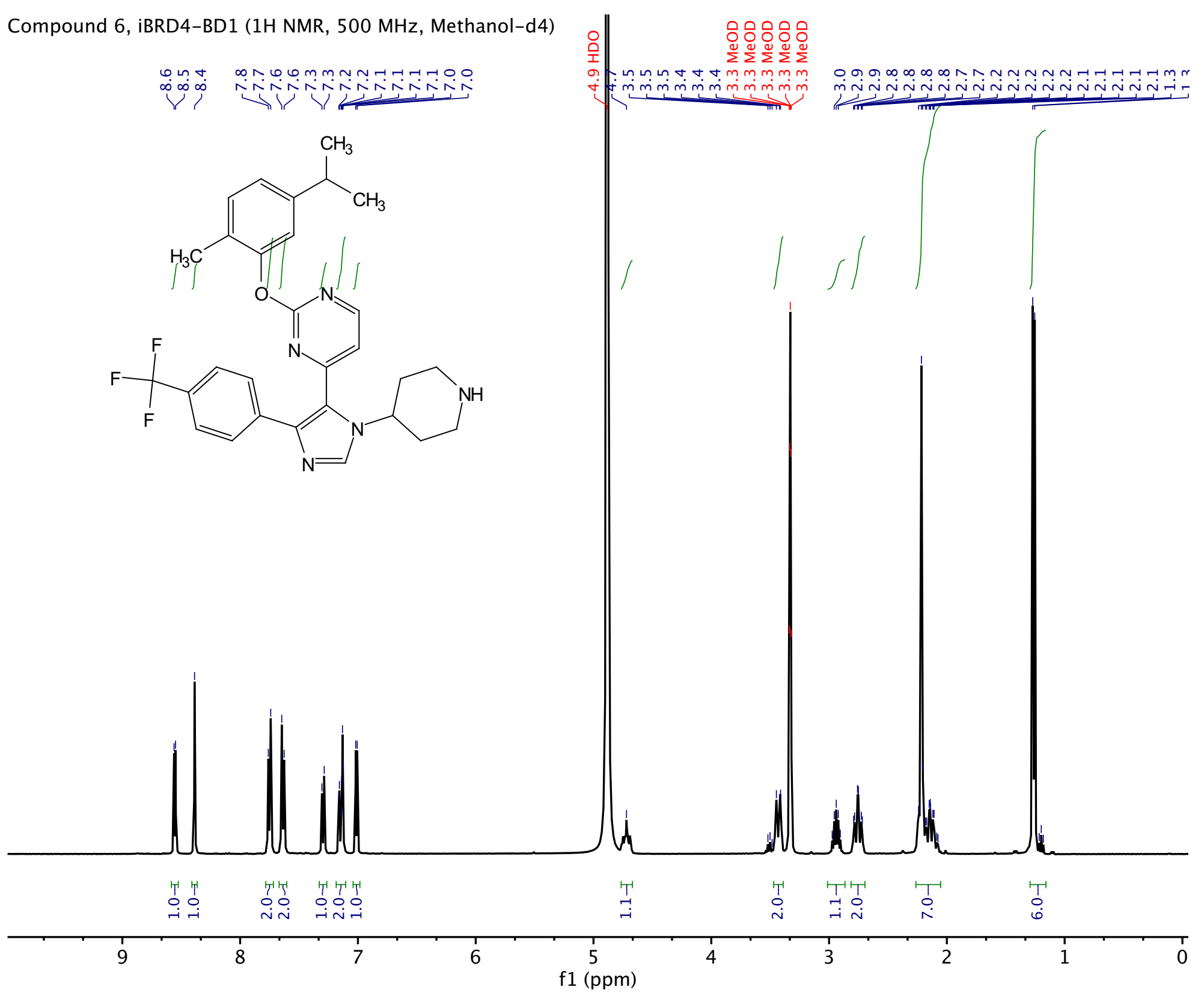




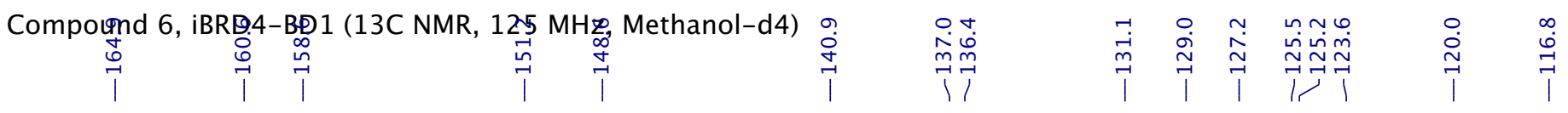

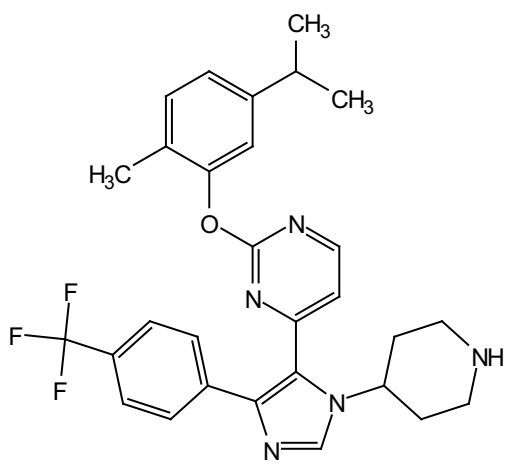

$\mid$ 
Compound 6, iBRD4-BD1 (19F NMR, 471 MH出, Methanol-d4)

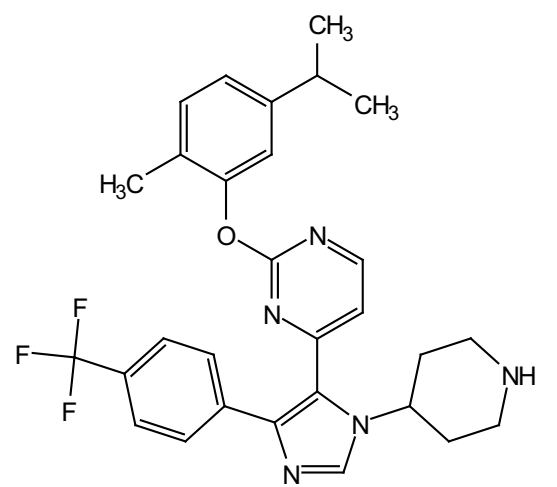

2xTFA
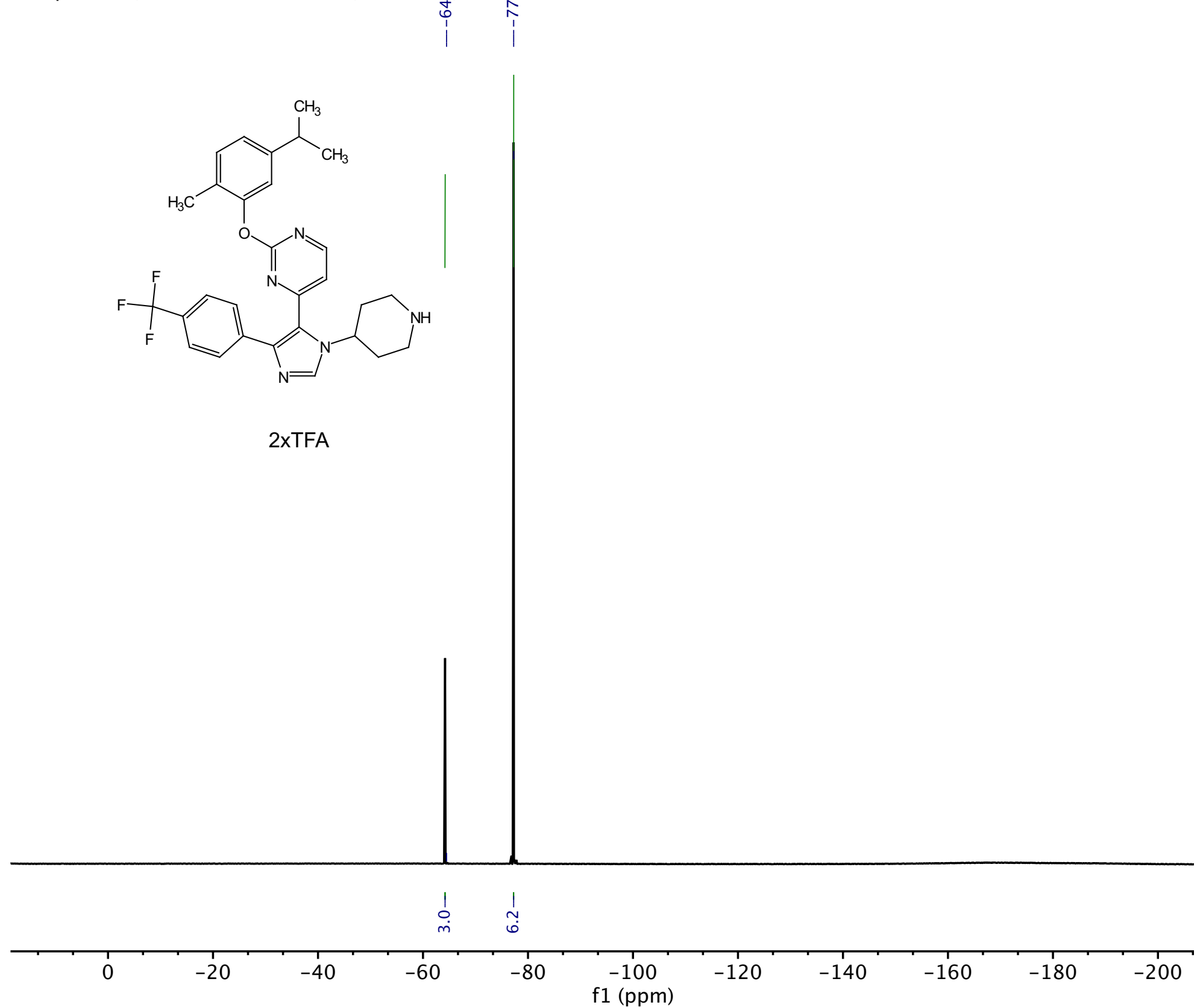
Compound 7 (lH NMR, 500 MHz, DMSO-d6)

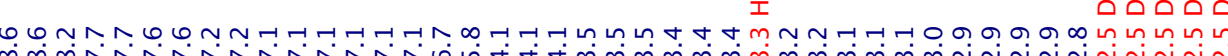

o.
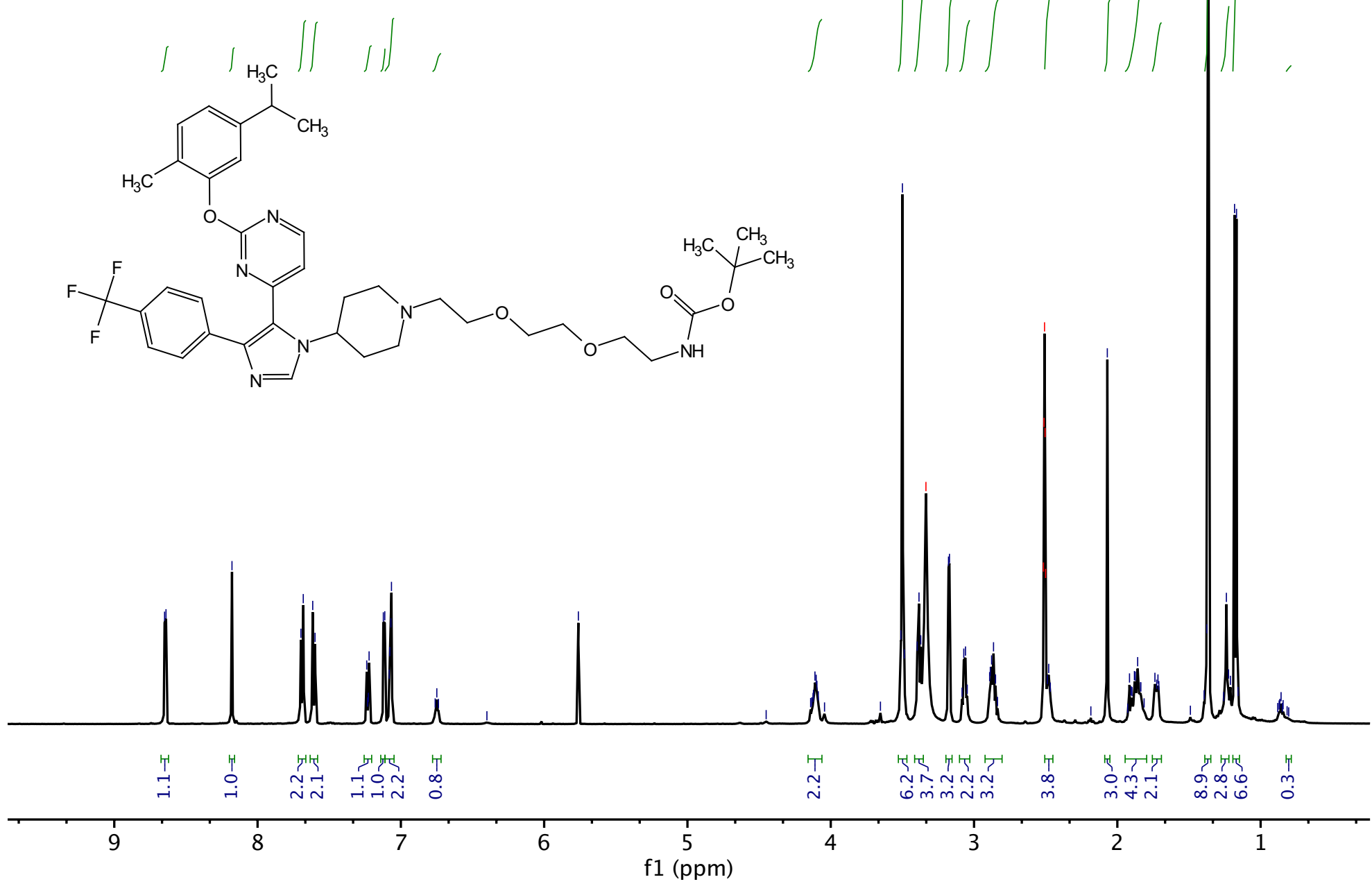
Compound 7 (13C NMR, 126 MHz, DMSO-d6) N

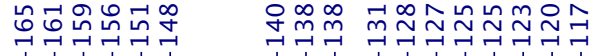

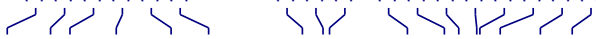

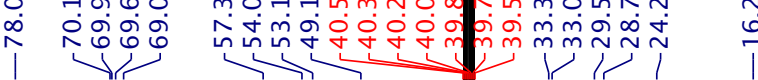<smiles>Cc1ccc(C(C)C)cc1Oc1nccc(-c2c(-c3ccc(C(F)(F)F)cc3)ncn2C2CCN(CCOCCOCCNC(=O)OC(C)(C)C)CC2)n1</smiles>

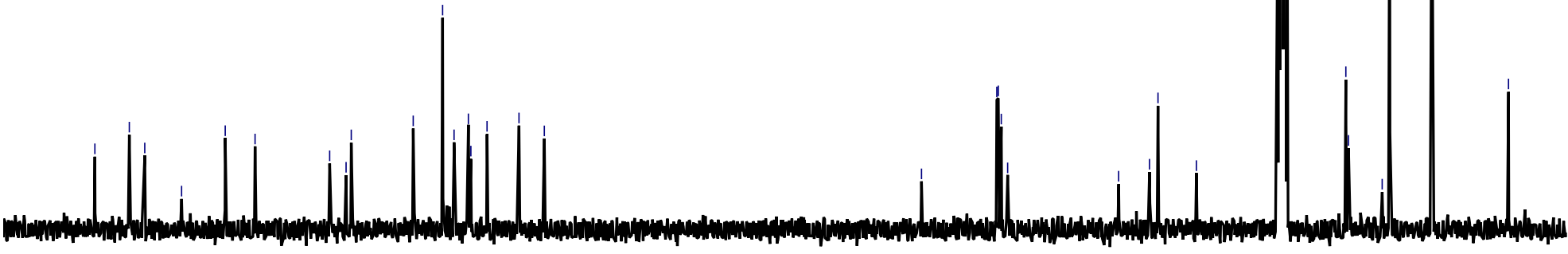




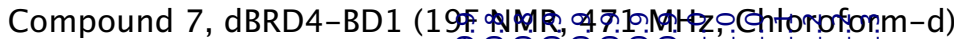
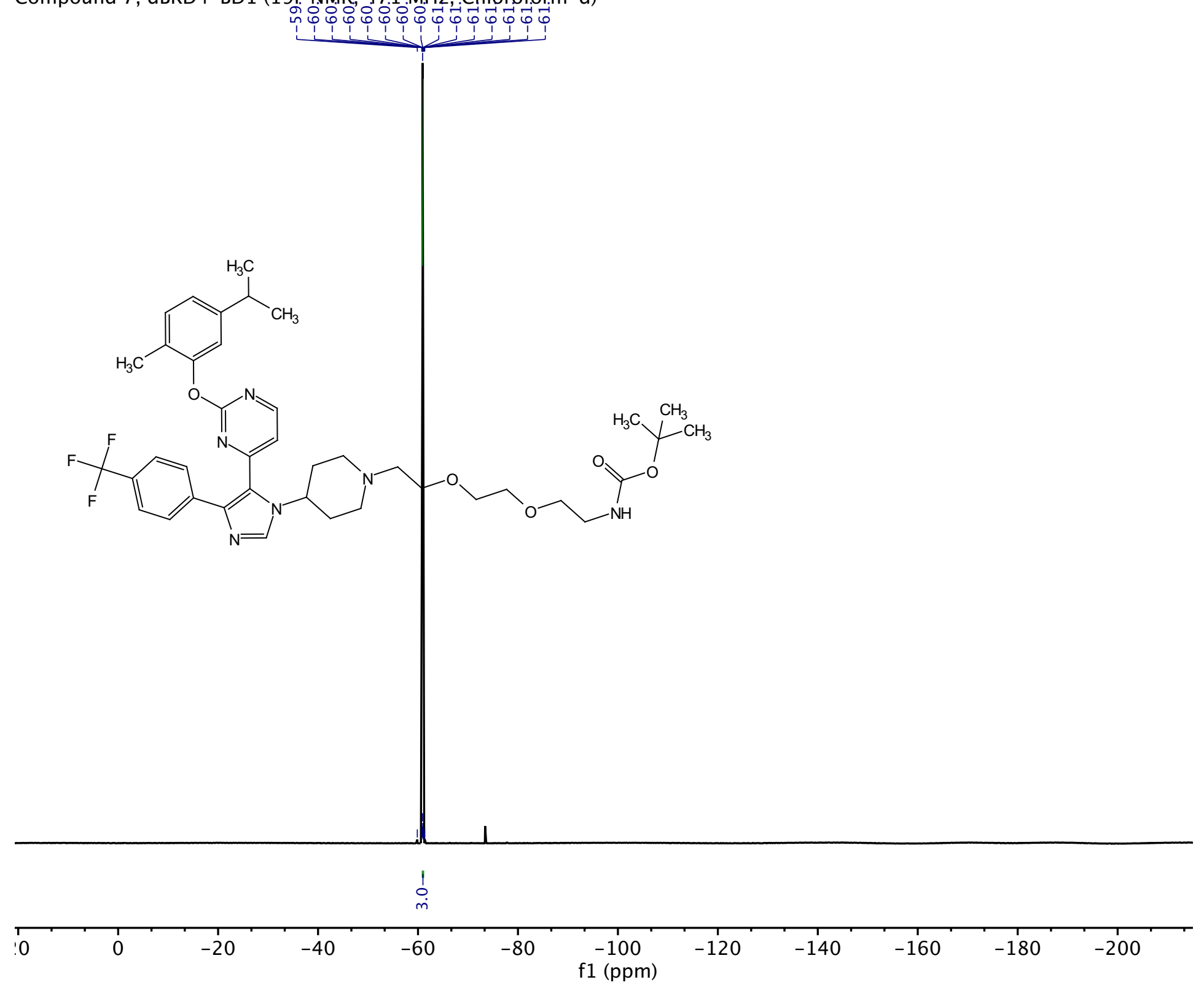
Compound 8, dBRD4-BD1 (1H NMR, 900 MHz, DMSO-d6)

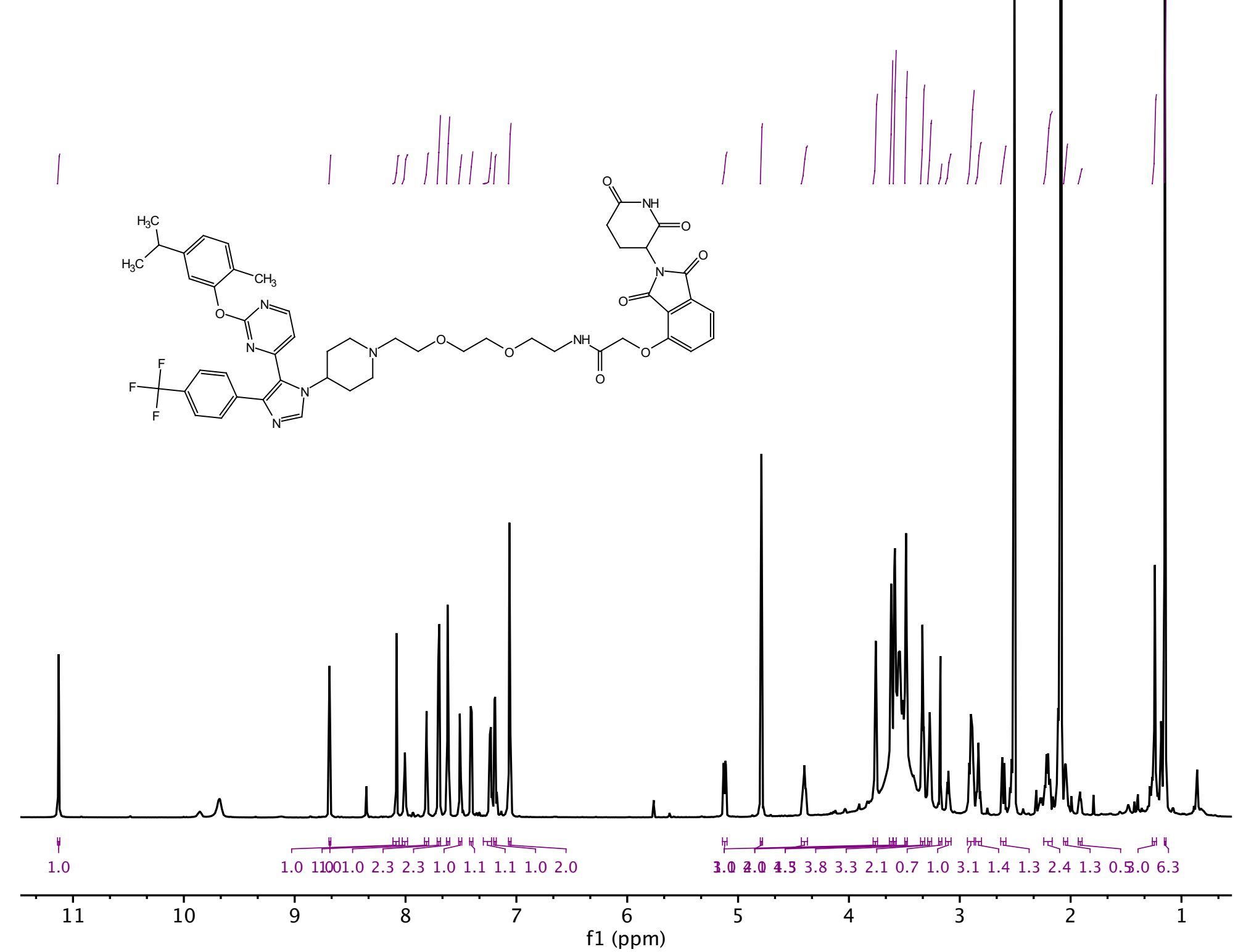




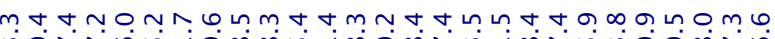

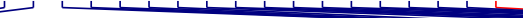

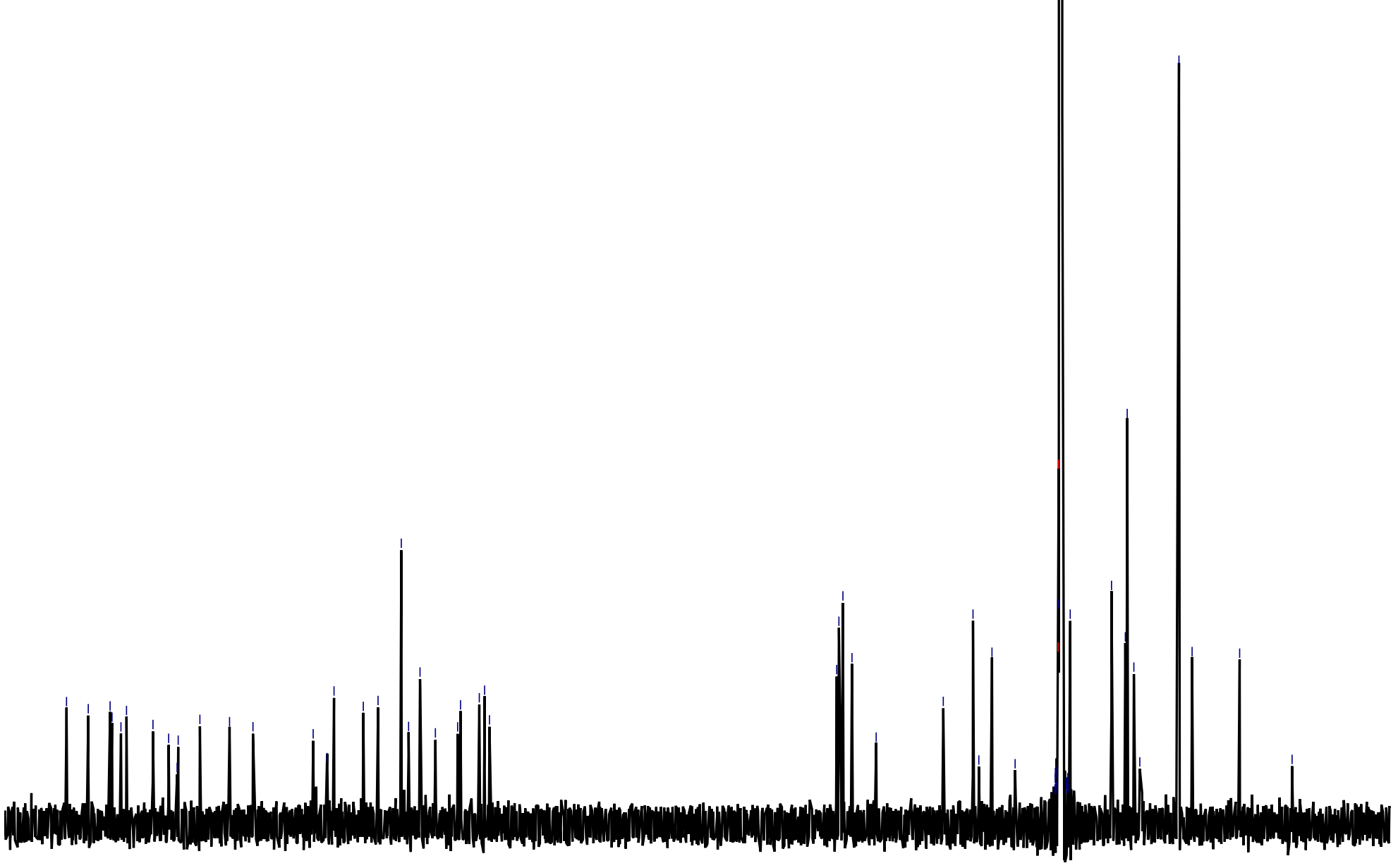


Compound 8, dBRD4-BD1 (19F NMR, $471 \$ 1 \mathrm{~Hz}$, Chpporoform-d)

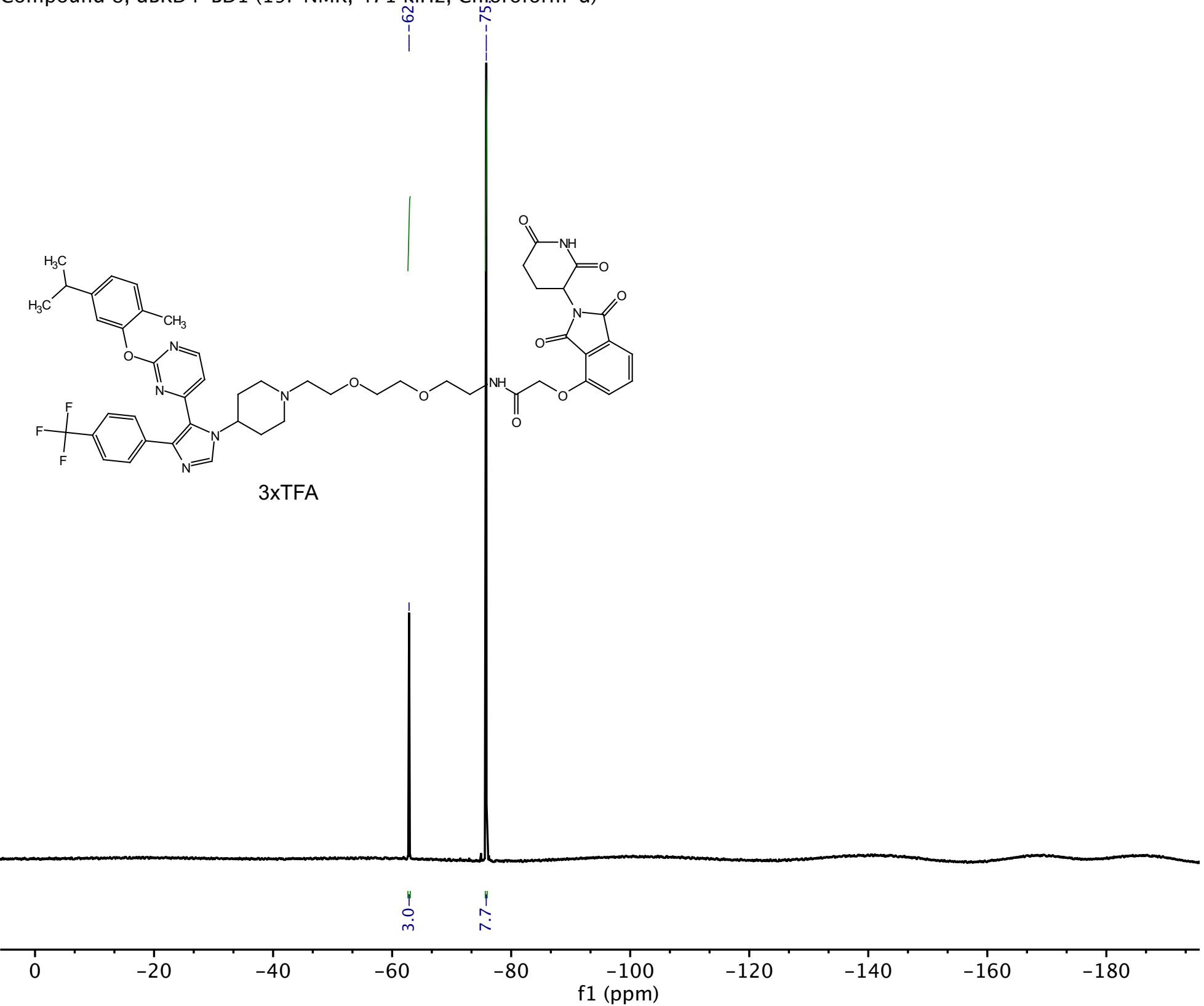

